\title{
A Numerical Study of the Gas-Liquid, Two-Phase Flow Maldistribution in the Anode of a High Pressure PEM Water Electrolysis Cell
}

\author{
Anders Christian Olesen ${ }^{\mathrm{a} 1}$, Carsten Rømer ${ }^{\mathrm{b}}$ and Søren Knudsen Kær ${ }^{\mathrm{a}}$ \\ ${ }^{a}$ Department of Energy Technology, Aalborg University, Pontoppidanstræde 101, 9220 Aalborg East, Denmark \\ ${ }^{\mathrm{b}}$ IRD A/S, Odense, Denmark
}

\section{Abstract:}

In this work, the use of a circular-planar, interdigitated flow field for the anode of a high pressure (HP) proton exchange membrane (PEM) water electrolysis cell is investigated in a numerical study. While PEM fuel cells have separated flow fields for reactant transport and coolant, it is possible to operate a PEM electrolysis cell with the anode flow field serving as both. This allows for a simpler system and a thinner design, however sets new and more strict requirements for the flow field to distribute uniformly. For the conducted numerical study, two computational fluid dynamics models are developed; a single-phase flow model for establishing the effect of geometry and a two-phase flow model for studying the effect of dispersed gas bubbles. Both models account for turbulence and heat transport. In the literature, previous studies on square-planar, interdigitated flow fields for PEM fuel cells have demonstrated particular advantages in regard to increasing the limiting current density and achieving a uniform distribution of properties. In the present study, it is however found that the circular-planar shape of the interdigitated flow field causes maldistribution. Moreover, under nominal conditions and below a water stoichiometry of 350, flow and temperature maldistribution is adversely affected by the presence of the gas phase; particularly gas hold-up near outlet channels can cause excessive formation of hotspots. As the water stoichiometry increases above a water stoichiometry of 350, the flow maldistribution increases. Nonetheless, its impact on the temperature distribution is counterbalanced by the overall increase in heat capacity of the flow. Hence, a relative uniform temperature distribution is achieved at and above nominal flow conditions. Finally, in a parametric investigation it is underlined that the predicted formation of hotspots is sensitive to the employed particle diameter of the two-phase channel flow model. The larger the particle size, the more severe the maldistribution of temperature becomes. It is therefore concluded that further experimental validation and research into particle size modeling is necessary.

\footnotetext{
${ }^{1}$ Corresponding author

Email address: aco@et.aau.dk, telephone number.: +45 21369153
} 
30

31 PEMEC; water electrolysis; modeling; two-phase flow; high pressure

33

34

35

36

37

38

39

40

41

42

43

44

45 


\section{Introduction}

With the growing need for grid balancing as a result of the use of renewable energy sources, the long-term storage of electricity in the form of chemical compounds is becoming increasingly more attractive [1-3]. Here particular, the production of hydrogen through water electrolysis has received increasing attention $[4,5]$. This interest has further been sparked by the growing demand for a hydrogen infrastructure in relation to fuel cells, particular associated with automotive applications, and as a chemical building block for synthetic fuels and in upgrading of biofuels.

As a technology, water electrolysis has been commercially available for more than a century. These systems have typically been alkaline based, bulky and suffered from poor dynamic response to load changes [5]. With the recent developments in proton exchange membrane electrolysis cells (PEMEC), a technology has been developed that offers significantly higher current densities, and in turn a more compact design. Even though the technology at the present time utilizes expensive noble metals as an electro-catalyst, the potential benefits, which include good partial load range, good dynamic response and high pressure operation, are believed to outweigh its shortcomings. [4]

In the electrolysis of water using a PEMEC, the overall reaction is split into two half-cell reactions occurring at the anode and cathode, respectively:

$$
\begin{gathered}
2 \mathrm{H}_{2} \mathrm{O} \rightarrow 4 \mathrm{H}^{+}+4 e^{-}+\mathrm{O}_{2} \\
2 \mathrm{H}^{+}+2 e^{-} \rightarrow H_{2}
\end{gathered}
$$

While electricity is supplied to the PEMEC, the anode is fed with demineralized water. Throughout the anode, oxygen is produced and a gas-liquid, two-phase flow develops. Similarly in the cathode, hydrogen is produced along the channel length. Since water can permeate the polymer membrane, a gas-liquid, two-phase flow also develops at the cathode. In order to provide cooling to the PEMEC, an excess amount of demineralized water is supplied relative to the stoichiometric conditions required in the anode half-cell reaction.

Although PEMEC are competitive on many levels, price and particularly durability still need to be improved. One way is by optimizing the flow and heat distribution across the cell. Because the incoming liquid water both serves as a fuel and coolant, an even distribution not only ensures good mass transport characteristics, it also allows for a uniform heat removal. If either of these two issues cannot be ensured, hotspots and catalyst degradation may occur. Moreover, as developers try to increase the nominal current density of PEMEC beyond a mark of $1 \mathrm{~A} / \mathrm{cm}^{2}$, the importance of a uniform heat removal becomes ever more acute.

A factor that both directly and indirectly affects the flow distribution is the operation pressure. On a system level, it has been shown favorable to apply some degree of pre-compression internally in the PEMEC. Although it increases the hydrogen crossover and the open circuit voltage, the total energy consumption decreases because of a reduction in the mechanical work associated with the subsequent compression [6,7]. The system topology and operation which has shown the highest efficiency is the so-called asymmetric configuration, where primarily the cathode is pressurized [7]. A disadvantage of the asymmetric configuration is that it 
81 imposes a large differential pressure across the PEM, which creates a large force on the gas diffusion layer 82 (GDL) of the anode, and the bipolar layer (BP). If the GDL is not properly selected, it may collapse, and similarly for the BP, it may break due to its often brittle nature.

To ensure mechanical stability at elevated pressures, as well as a uniform distribution of flow and heat, certain requirements apply to material strength and cell geometry. As opposed to PEMFC, circular-planar cells are used instead of square-planar cells. Evidently, this difference in geometry affects the channel design, and thus the distribution of temperature and flow. Another difference that affects channel design is the difference in twophase morphology. In PEMFC the two-phase flow consists of a continuous gaseous phase and a dispersed liquid water droplets phase, however in PEMEC this is only true for the cathode. In the anode the continuous phase consists of liquid water and dispersed oxygen bubbles.

91 For square-planar cells three archetype channel configurations are traditionally preferred [8], i.e. parallel, serpentine and interdigitated channels, although many more exist [9], e.g. pin-type or integrated flow field. While parallel and serpentine channels distribute reactants over a porous GDL, through which species mainly diffuse, interdigitated channels force convective flow through the GDL. Although serpentine flow fields allow some extent of cross-convective transport, interdigitated flow fields offer significantly better mass transport characteristics. Even so, this enhanced mass transport comes at the expense of a substantial increase in pressure loss. For applications where a high flow and a low pressure loss are required, parallel channels are typically chosen. However, for systems subject to two-phase flow, parallel channels suffer from a high extent of maldistribution. This may occur because a single channel might become blocked by a gas bubble or a liquid droplet. To limit the extent of maldistribution, while keeping a low pressure loss, combinations of parallel and serpentine channels are by now the "industrial standard" [10]. These flow fields are in most cases the best compromise in partially flooded conditions.

103 In the literature, various experimental and modeling studies have been conducted with the aim of 104 characterizing square-planar, interdigitated flow fields for PEMFC [11-20], however none are available for 105 PEMEC. In the studies conducted on PEMFC, focus has often been on comparing interdigitated flow fields with parallel or serpentine, or analyzing the effect of various operation conditions.

In the first published study on interdigitated flow fields, Nguyen [11] made an experimental comparison between a straight and interdigitated channel structure. Their study showed that an enhanced performance could be obtained by moving the onset of the limiting current density, when mass transport was the limiting factor. This conclusion was further substantiated in the more comprehensive experimental work by Wood et al. [21]. Here, it was underlined that the observed mass transport improvement had two main causes. First of all, the main transport mechanism of species is altered from diffusion to convection dominated. Secondly, entrapped liquid water is removed from the GDL by a high shear force exerted by the gas flow.

114 In the modeling studies to follow [15,22-24], emphasis was on establishing the effect of gas flow rate, humidity, and GDL thickness on the performance and current density distribution. In these studies, it was shown that the observed performance improvement is a complex interplay between diffusion and convection phenomena as well as liquid water transport and evaporation. Wang et al. [14] further studied the significance 
of pressure, temperature and humidity. Their work showed that performance is particularly sensitivity towards humidity changes, even more pronounced than for serpentine flow fields.

120 Studies on water transport visualization in interdigitated flow fields have also been conducted. Owejan et al.

121 [25] used neutron radiography in both the GDL and channels. Their results showed that GDL flooding primarily 122 occurs near the outlet channels. Moreover, it was concluded that the effect of gas phase shear force cannot in 123 itself explain water removal, when evaporation is eliminated. It was hypothesized that capillary transport plays 124 a vital role. Su et al. [18] used a transparent bipolar plate for studying water flooding in the channels. In 125 addition to the previous observed water flooding near outlet channels, flooding was observed near channel corners. The latter was attributed to a higher contact area and hence higher viscous resistance to water flow.

In the experimental work by W. M. Yan et al. $[13,26]$, the effect of the land-to-channel area ratio in connection with varying operating conditions was studied. The same focus was seen in the modeling studies by X.D. Wang et al. $[12,16]$. In all these studies, a common conclusion emerged; using an interdigitated flow field, performance is less sensitive to the number of channels and their geometry than straight channels for a constant area ratio. In a later modeling study by Berning et al. [27], the effect of two-phase flow was studied in much more detail. In their model, detailed phenomena associated with heat and liquid water removal were taken into account. It was hereby underlined that an improved waste heat removal could be obtained with interdigitated flow fields. Later, Berning et al. [28] further demonstrated that interdigitated flow fields enable low stoichiometric operation which effectively reduces the required back pressure.

For PEMEC the available number of publications is scarce. A few studies have investigated the effect of gasliquid, two-phase flow in the anode using parallel and serpentine flow fields in PEMEC at atmospheric pressures. Ito et al. 2010 [29] found in their experimental study that these flow fields are sensitive to the twophase flow regime. At high current densities when a large amount of oxygen is produced, slug or annular twophase flow develops and obstructs the liquid phase reactant flow towards the catalyst layer. In the numerical modeling study by Nie and Chen [30] it was further shown that a high extent of flow maldistribution could occur and even reversed flow in some channels.

Although the use of an interdigitated, square-planar flow field in PEMFC has been shown to offer particular benefits in avoiding mass transport limitations induced by gas-liquid, two-phase flow, no studies have been published on interdigitated, circular-planar flow fields for PEMEC. In particular, the consequence of using circular-planar, interdigitated flow fields for the anode is unknown. Moreover, studies on interdigitated flow fields for PEMFC have only focused on mass transport in partially flooded conditions; hence conclusions are not directly transferrable to PEMEC.

The main objective of this work is therefore the investigation of the flow and temperature maldistribution in an interdigitated anode flow field using a macroscopic, three-dimensional model. While a single-phase model is used for highlighting the effect of the geometry on maldistribution, a two-phase model is used for understanding the effect of the gas-liquid flow interaction on maldistribution. Both models account for mass layer (MPL), a mass flux boundary condition based on a uniform current density distribution is applied. The 
devised models are studied under nominal conditions as well as by varying the water stoichiometry and particle diameter size. The latter is done, to investigate the sensitivity of the two-phase model to applied particle size.

The paper is organized as follows. Initially, a short description of the geometry, porous medium, heating, and turbulence is given. Then the mathematical models, numerical solver and data treatment will be presented, followed by a results and discussion section. Finally, the paper is ended with a conclusion.

\section{Methodology}

\subsection{Geometry}

In this work, the interdigitated, circular-planar anode flow field shown in Figure 2-1 is used. It consists of one inlet, one outlet, an interdigitated channel structure and a porous medium. There are 8 incoming and 9 outgoing channels in the interdigitated channel structure. Each channel has a width of $1 \mathrm{~mm}$ and height of 0.5 $\mathrm{mm}$. The inlet manifold has a height of $1 \mathrm{~mm}$ and width of $5 \mathrm{~mm}$. The diameter of the circular GDL is $9.4 \mathrm{~cm}$.

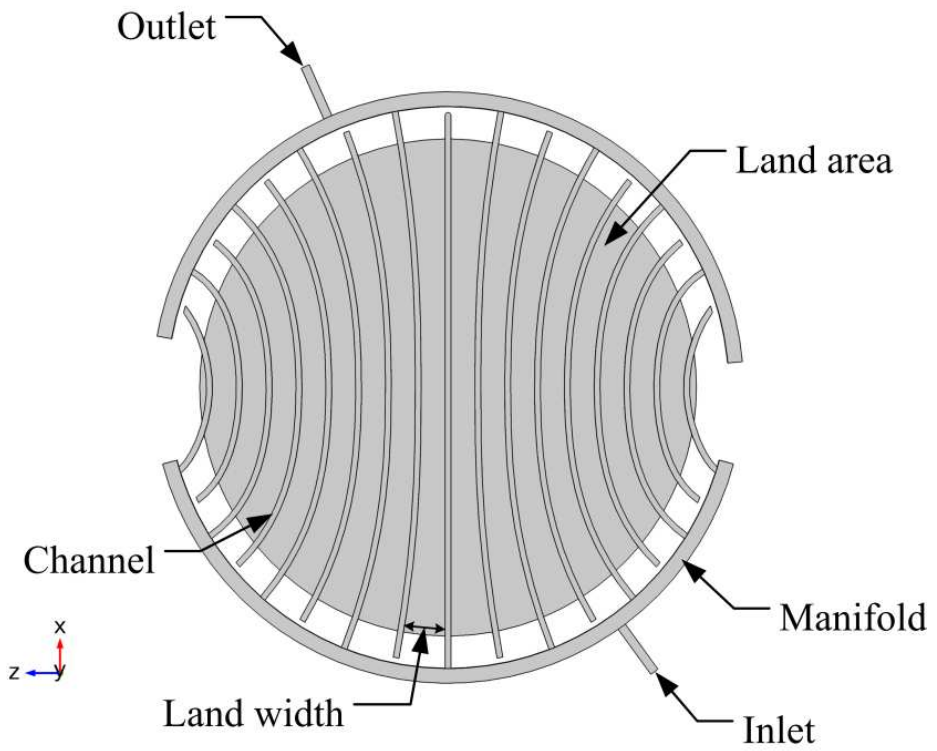

Figure 2-1: Anode planar-circular flow field

Because of the high operating pressure of the cathode, the channels are thin compared to the land width. This prevents that the porous GDL intrudes into the channels and not to mention, improves the structural integrity of the BP. Moreover, the channels are curved to achieve a more even flow distribution throughout the GDL along the channel length.

\subsection{Porous Medium}

For the anode GDL to withstand the resulting forces, a material is required with a high tensile strength. Typically, random organized titanium fibers are therefore used. These are untreated and are hence purely 
hydrophilic by nature. In this work, the titanium felt (Ti-felt) from Bekaert Toko Metal Fiber Co. Ltc was used as a reference. It has a fiber diameter of 20 micrometer, a weight of $300 \mathrm{~g} / \mathrm{cm} 2$, a porosity of $81 \%$ and a thickness of $0.35 \mathrm{~mm}$. In Figure 2-1, the characteristic dependence of the Ti-felt as a function of compression pressure is shown. From left to right, the material strain, viscous permeability and volume porosity are depicted, respectively.

The strain of the Ti-felt was measured by initially compressing, relaxing and re-compressing. The recompressing was repeated a couple of times to establish the extent of plastic deformation. From these test it is apparent that the Ti-felt permanently deforms after the first compression. The permanent deformation is more than $15 \%$ of its initial thickness.
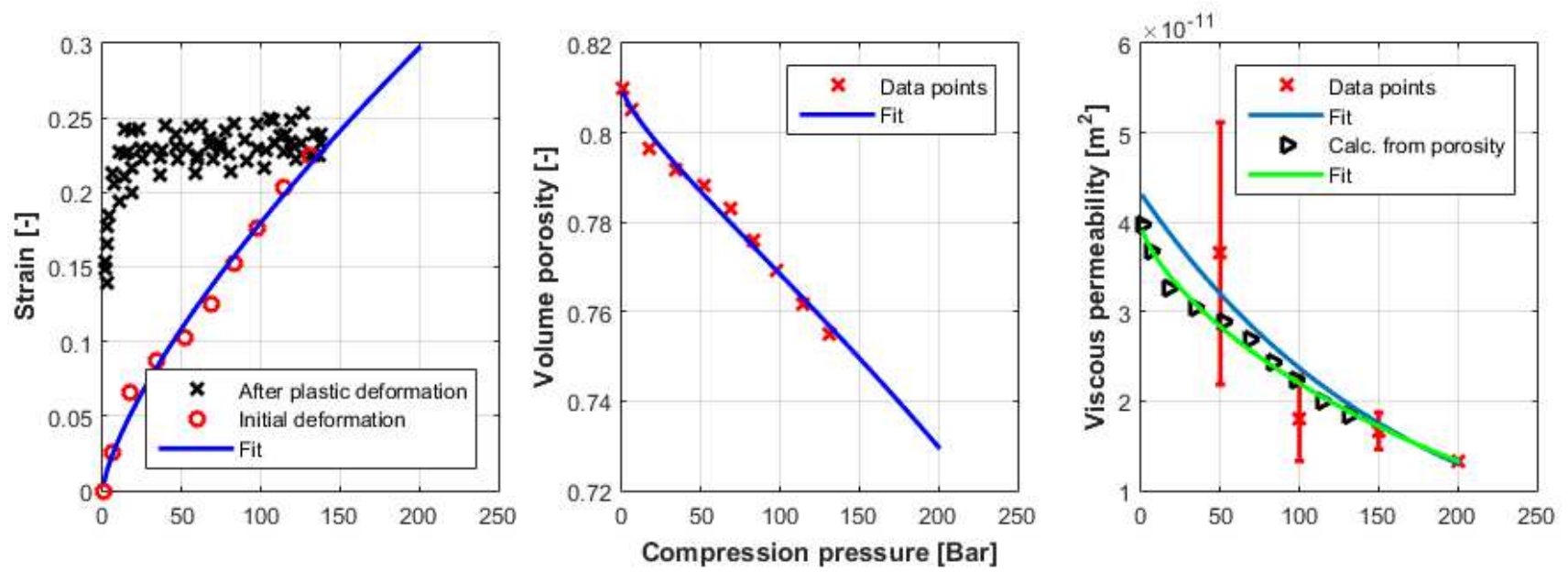

Figure 2-2: Titanium felt deformation strain, viscous permeability and volume porosity as function of deformation pressure

In order to determine the functional dependence of the volume porosity on compression pressure, the initial volume porosity without compression was measured and then using the following formula re-calculated as function of the measured strain [31]:

$$
\varepsilon=1-\frac{1}{s}\left(1-\varepsilon_{0}\right)
$$

Here $s$ denotes engineering strain as function of compression pressure and $\varepsilon_{0}$ the initial volume porosity.

From these calculations, a fairly linear dependence is visible on compression pressure. It should be noted that the material only shows a minor decrease in volume porosity even at 200 bars.

The in-plane, viscous permeability was found by compressing the fibrous Ti-felt and then measuring the pressure loss as function of volume flow. This was repeated for four different compression pressures. For each compression pressure, a Darcy-Forchheimer relation was fitted to the pressure-loss and volume flow data: 


$$
\Delta p=\frac{\mu}{K} u+\rho \beta u^{2}
$$

Here $K$ denotes viscous permeability, $\mu$ viscosity, $u$ superficial velocity, $\rho$ density and $\beta$ inertial Forchheimer coefficient. In Figure 2-2 the measured viscous permeabilities and $95 \%$ confidence intervals are plotted. As a reference, the calculated volume porosity is correlated to the viscous permeability predicted using the relation by Tomadakis and Robertson [32] for 2D fibrous structures. Evidently, there is some discrepancy between the data and the estimated values from the volume porosity measurements. Nonetheless, both data sets are within the calculated $95 \%$ confidence intervals. It should be noted that although the permeability decreases exponentially by approximately a factor of 4 from 0 to 200 bar compression, the fibrous Ti-felt remains relative permeable.

\subsection{Heat Generation}

In order to evaluate the heat flux generated per cell during water electrolysis, the reversible and irreversible heat generation needs to be evaluated. Here the reversible heat is calculated as the difference between the usable work in terms of Gibbs free energy and the enthalpy of reaction, which constitutes the maximum available energy:

$$
Q_{\text {rev }}=-T \Delta S=\Delta G^{\circ}-\Delta H^{\circ}=n F V_{\text {rev }}-\Delta H^{\circ}
$$

Here $Q$ denotes heat generation per mole, $T$ absolute temperature, $S$ entropy, $G$ Gibbs free energy and $H$ enthalpy. The irreversible heat is the heat generated from driving the electrochemical reactions and transporting ions and electrons. It is calculated as the difference between the reversible and irreversible cell potential:

$$
Q_{\text {irr }}=\left(V_{\text {cell }}-V_{\text {rev }}\right) n F
$$

Here $V$ is voltage, $n$ is the number of electrons transferred during the electrochemical reactions and $F$ is Faradays constant. The heat flux generated per cell $q$ is then given as the sum of the reversible and irreversible heat generation multiplied by the number of moles reacting

$$
q=\left(Q_{\text {irr }}+Q_{\text {rev }}\right) \dot{N}=\left(V_{\text {cell }}-\frac{\Delta H^{\circ}}{n F}\right) I_{\text {cell }}
$$

The cell current can be found by integrating current density:

$$
I_{\text {cell }}=\int_{A_{c}} j d A
$$

It should be noted that the point where the cell voltage is equal to the change in enthalpy over the number of electrons being transferred times Faradays constant, is defined as the thermo-neutral point: 


$$
V_{\text {neutral }}=\frac{\Delta H^{\circ}}{n F}
$$

226 At the thermo-neutral point no heat is generated or required for the electrochemical reaction to take place.

227 Above heat is generated and below heat is consumed.

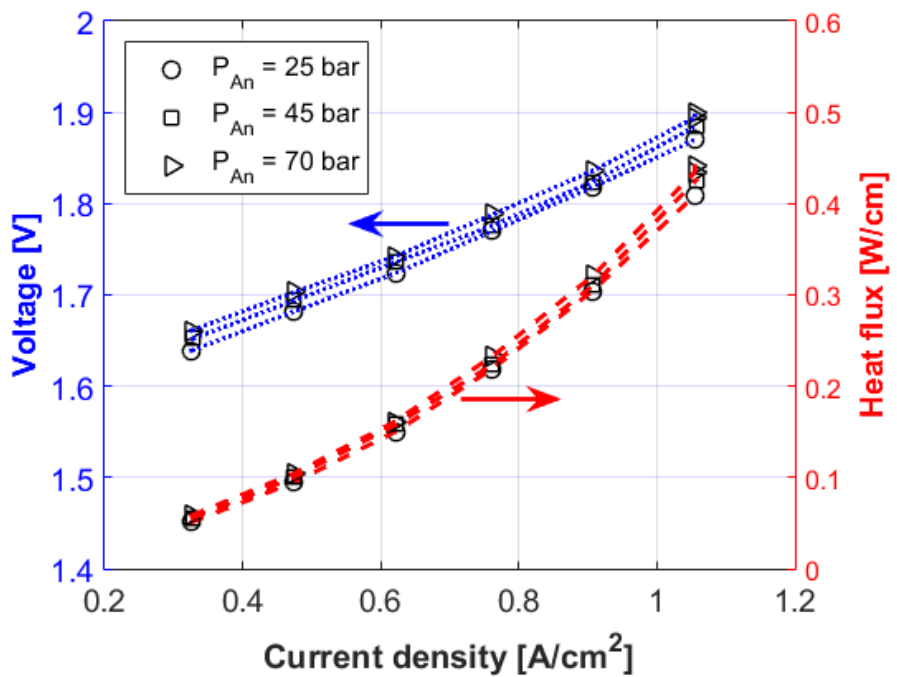

Figure 2-3: Polarization curve and heat generation of a PEMEC per unit area at $70 \mathrm{C}$, cathode pressure of 1.8 bar and different anode pressures.

231 In Figure 2-3, the resulting heat flux of a water electrolysis stack consisting of 33 cells is shown. The electrolysis 232 cell is operated at three different cathode pressures for a fixed water stoichiometry of 350 and fixed outlet temperature of $70^{\circ} \mathrm{C}$. The $y$-axis to the left depicts cell voltage, while the $y$-axis to the right shows the resulting heat flux per cell. The plotted heat flux is positive under the applied conditions and depicts a non-linear dependence on current density. This interplay illustrates that the requirement for cooling significantly increases with increasing current density. Furthermore, the higher the anode pressure, the higher the cell voltage and heat flux becomes. However, this effect is minor compared to the dependence on current density.

\subsection{Turbulence}

Because cooling is achieved through running water electrolysis at excess amounts of water, high flow rates are seen. In fact, under nominal conditions the flow may become turbulent. In Table 1 the superficial Reynolds number is depicted as function of water stoichiometry for two positions: the manifold inlet and one of the interdigitated channel inlets. In the latter case a uniform distribution among the channels is assumed. The superficial Reynolds number and water stoichiometry are defined as follows:

$$
\operatorname{Re}=\frac{\rho D_{H} u}{\mu}
$$




$$
\lambda_{\mathrm{H}_{2} \mathrm{O}}=\frac{\dot{m}_{i n} 2 F}{M_{w, H_{2} O} \int_{A_{c}} j d A}
$$

246 Here $D_{H}=2 a b /(a+b)$ is the hydraulic diameter, $\dot{m}_{i n}$ is the inlet mass flow rate and $M$ is the molecular 247 weight.

Table 1: Superficial Reynolds number as a function of water stoichiometry for a current density of $1 \mathrm{~A} / \mathrm{cm}^{2}$

\begin{tabular}{|l|l|l|c|r|}
\hline & \multicolumn{2}{|c|}{ Manifold } & \multicolumn{2}{c|}{ Interdigitated channels } \\
\hline Water stoichiometry & 200 & 500 & 200 & 500 \\
\hline Superficial Reynolds number & 2044 & 5110 & 426 & 1065 \\
\hline
\end{tabular}

While the flow in the inlet region moves from being transitional (i.e. $R e=2100-4000$ ) to fully turbulent (i.e. $\operatorname{Re}$ $>4000$ ) as a function of water stoichiometry, the flow in the interdigitated channels remains in the laminar regime (i.e. Re < 2100) for all water stoichiometries. Meanwhile, it should be noted that the superficial Reynolds number only accounts for shear induced turbulence. Hence, it does not reveal anything about the particle induced turbulence in the gas-liquid, two-phase flow, or the effect of fibers intruding into the interdigitated channel. Hence, it is to be expected that the onset of turbulence occurs at lower superficial Reynolds numbers.

\subsection{Assumptions}

A number of assumptions are made in order to simplify the extent of the mathematical model:

- Current density and heat is produced uniformly across the active surface area.

- Due to a high anode pressure the molar fraction of water vapor is neglected, hence phase change and associated cooling or heating effects are likewise neglected.

- The crossover of water, hydrogen and oxygen is neglected.

- The effect of cooling due the bipolar plate redistributing heat is neglected.

\subsection{Mathematical Model}

In order to model single- and two-phase flow in the anode, two different models are required. Both models have to account for continuity and momentum conservation within channels and porous domain. At the applied range of mass flows, turbulent flow develops. To model turbulence, the Menter's Shear Stress Transport (SST) model is used. This type of turbulence model is a two-equation, eddy viscosity turbulence model [33].

\subsubsection{Single-phase flow}

\subsubsection{Continuity and momentum conservation}

The macroscopic, volume-averaged, steady-state continuity and momentum equations are modeled as follows: 


$$
\nabla \cdot(\varepsilon \rho \mathbf{U})=\varepsilon S_{c}
$$

$$
\nabla \cdot(\varepsilon \rho \mathbf{U} \mathbf{U}-\varepsilon \boldsymbol{\tau})=-\varepsilon \nabla p+\varepsilon \rho \mathbf{g}+\varepsilon \mathbf{M}
$$

Here $\varepsilon$ denotes volume porosity, $\rho$ is density, $\mathbf{U}$ is the intrinsic or true velocity, $S_{c}$ is a mass source term, $\boldsymbol{\tau}$ is the viscous stress term, $p$ is pressure, $\mathbf{g}$ is the gravity force and $\mathbf{M}$ is the generalized momentum source term. The generalized momentum source term is equal to Darcy's law in the porous domain and zero elsewhere:

$$
\mathbf{M}=\left\{\begin{array}{cc}
\mathbf{K}^{-1} \mu \varepsilon \mathbf{U}, & \Omega \in \mathrm{GDL} \\
0, & \Omega \in \text { Channel }
\end{array}\right.
$$

Here $K$ denotes viscous permeability and $\mu$ is the viscosity. The viscous stress term can be modeled as follows:

$$
\begin{gathered}
\tau=\left(\mu+\mu_{T}\right)\left(\nabla \mathbf{U}+(\nabla \mathbf{U})^{T}-\frac{2}{3}(\nabla \mathbf{U}) \mathbf{I}\right) \\
\mu_{T}=\rho \frac{k}{\omega}
\end{gathered}
$$

Here $\mu_{T}$ is the turbulent eddy viscosity, $k$ is the turbulent kinetic energy and $\omega$ is the turbulent eddy frequency.

\subsubsection{Thermal energy conservation}

The transport of energy at low velocities can be modeled using the thermal energy conservation equation:

$$
\nabla \cdot\left(\varepsilon \rho \mathbf{U} h-\varepsilon\left(\lambda+C_{P} \frac{\mu_{T}}{\operatorname{Pr}_{T}}\right) \nabla T\right)=\boldsymbol{\tau}: \nabla \mathbf{U}+\mathbf{S}_{E}
$$

Here $h=e+\frac{P}{\rho}$ is the specific enthalpy, and $\mathbf{S}_{E}$ is the energy source term.

\subsubsection{Turbulence}

The effect of turbulence is modeled using the eddy viscosity hypothesis, where the effect of Reynolds shear stress is assumed proportional to the mean rates of deformation. In this work, the SST formulation by Menter et al. [33] is used for modeling the transport of the turbulent kinetic energy and turbulent eddy frequency:

$$
\nabla \cdot\left(\varepsilon \rho \mathbf{U} k-\varepsilon\left(\mu+\frac{\mu_{t}}{\sigma_{k}}\right) \nabla k\right)=P_{k}-\beta^{\prime} \rho k \omega+P_{k b}
$$




$$
\nabla \cdot\left(\varepsilon \rho \mathbf{U} \omega-\varepsilon\left(\mu+\frac{\mu_{t}}{\sigma_{k}}\right) \nabla \omega\right)=\alpha \frac{\omega}{k} P_{k}-\beta \rho k \omega^{2}+P_{\omega b}
$$

296

Here $P_{k b}$ and $P_{\omega b}$ are the buoyancy turbulence production and dissipation terms, respectively, and $P_{k}$ is the turbulence production due to viscous forces. Both terms are given as follows:

$$
\begin{gathered}
P_{k b}=-\frac{\mu_{T}}{\rho \sigma_{\rho}} \mathbf{g} \nabla \rho \\
P_{\omega b}=\frac{\omega}{k}\left[(\alpha+1) C_{3} \max \left(P_{k b}, 0\right)-P_{k b}\right] \\
P_{k}=\mu_{T}\left(\nabla \mathbf{U}+(\nabla \mathbf{U})^{T}-\frac{2}{3}(\nabla \mathbf{U}) \mathbf{I}\left(3 \mu_{T} \nabla \mathbf{U}+\rho k\right)\right)
\end{gathered}
$$

Here $\alpha=5 / 9$ and $C_{3}=1$ are model constants.

\subsubsection{Two-phase flow}

\subsubsection{Continuity and momentum conservation}

As opposed to the single-phase model, the two-phase model solves for two sets of macroscopic volumeaverage, steady-state equations, rather than one set. For the continuity and momentum conservation this gives in total 8 equations, as opposed to 4 in the case of single phase flow:

$$
\begin{gathered}
\nabla \cdot\left(s_{\alpha} \varepsilon \rho_{\alpha} \mathbf{U}_{\alpha}\right)=s_{\alpha} \varepsilon S_{c, \alpha} \\
\nabla \cdot\left(\varepsilon s_{\alpha} \rho_{\alpha} \mathbf{U}_{\alpha} \mathbf{U}_{\alpha}-\varepsilon s_{\alpha} \tau_{\alpha}\right)=-\varepsilon s_{\alpha} \nabla p_{\alpha}+\varepsilon s_{\alpha} \rho_{\alpha} \mathbf{g}+\varepsilon s_{\alpha} \mathbf{M}_{\alpha}
\end{gathered}
$$

Here $s$ denotes phase volume fraction, or what is called saturation, when dealing with porous media, and the subscript $\alpha \in[l, g]$ each thermodynamic phase; liquid and gas. This type of model is known as a two-fluid model and essentially assumes two interpenetrating continua. Coupling between each phase is achieved through the use of interfacial transport terms.

In the momentum equation interfacial transport is accounted for in the generalized momentum source term as follows:

$$
\mathbf{M}_{\alpha}=\left\{\begin{array}{l}
\mathbf{K}^{-1} \frac{\mu_{\alpha} s_{\alpha} \varepsilon}{k_{r e l, \alpha}} \mathbf{U}_{\alpha}, \quad \Omega \in \mathrm{GDL} \\
\pm\left(\mathbf{F}_{D}+\mathbf{F}_{T D}\right), \quad \Omega \in \text { Channel }
\end{array}\right.
$$



dispersion force. Inside the GDL porous resistance dominates, drag can be neglected. The interfacial drag term 318 is modeled as follows:

$$
\mathbf{F}_{D}=a_{c d} \rho_{g} C_{D}\left|\mathbf{U}_{g}-\mathbf{U}_{l}\right|\left(\mathbf{U}_{g}-\mathbf{U}_{l}\right)
$$

Here $a_{c d}$ is the interfacial area density and $C_{D}$ is the drag coefficient. The drag coefficient is modeled using the Ishii Zuber drag law for densely distributed fluid particles. For the dense spherical particle regime, the model takes the following form:

$$
\begin{gathered}
C_{D}=\frac{24}{R e_{l}}\left(1+\frac{1}{6} R e_{l}^{\frac{2}{3}}\right) \\
R e_{l}=\frac{d \rho_{l}\left|\mathbf{U}_{l}-\mathbf{U}_{g}\right|}{\mu_{m}} \\
\frac{\mu_{m}}{\mu_{l}}=\left(1-\frac{s_{g}}{s_{d m}}\right)^{-2.5 s_{d m} \mu_{*}} \\
\mu_{*}=\frac{\mu_{g}+0.4 \mu_{l}}{\mu_{g}+\mu_{l}}
\end{gathered}
$$

Here $s_{d m}=1$ is the maximum packing value.

Interphase turbulent dispersion force is modeled using a Favre averaged interphase drag model:

$$
\mathbf{F}_{l, T D}=-\mathbf{F}_{g, T D}=C_{T D} C_{c d} \frac{\mu_{t l}}{\rho_{l} \sigma_{t l}}\left(\frac{\nabla s_{g}}{s_{g}}-\frac{\nabla s_{l}}{s_{l}}\right)
$$

Here $C_{c d}=1$ is the momentum transfer coefficient for the interphase drag force.

In addition to the shear induced eddy viscosity given by the turbulence model, particle induced turbulence in the liquid phase is accounted for using the implementation by Sato [34]. The additional liquid phase eddy viscosity is now given by:

$$
\begin{gathered}
\mu_{T, l}=\mu_{T s}+\mu_{T p} \\
\mu_{T p}=C_{\mu p} \rho_{l} s_{g} d_{p}\left|\mathbf{U}_{g}-\mathbf{U}_{l}\right|
\end{gathered}
$$


Here $C_{\mu p}=0.6$ is an empirical constant.

337 In two-fluid modeling it is customary to assume that all phases share the same pressure field. This assumption 338 is in most cases acceptable for free flow; however within the GDL the pores are so small that capillary pressure effects need to be accounted for when two immiscible fluids are present. By definition, the capillary pressure is given as the pressure difference between the non-wetting and wetting phase in the following manner:

$$
p_{c}=p_{g}-p_{l}
$$

Here it is assumed that the liquid phase is the wetting phase and the gas the non-wetting phase. In order to introduce this condition in the model, while only solving for one pressure field, an additional momentum source term needs to be added to either phase. In this work it is assumed that we solve for the liquid phase pressure, hence a momentum source term is added to the gas phase as follows:

$$
\mathbf{S}_{g M}=-\nabla p_{c}
$$

Different types of models exist for relating the saturation and the capillary pressure of a porous medium; some more mechanistic by nature than others. A popular one is the van Genuchten model [35]:

$$
p_{c}=p_{c b}\left(s_{e}^{-1 / m}-1\right)^{1 / n}
$$

Here $m$ and $n$ are empirical constants, $s_{e}$ is the effective saturation of the porous medium and $p_{c b}$ is the break through pressure. The effective saturation is related to the saturation as follows:

$$
s=s_{e}\left(1-s_{r}\right)+s_{r}
$$

Again, applying the van Genuchten model yields the following relations for the relative permeability of each phase as a function of saturation [36]:

$$
\begin{aligned}
& k_{r w p}=s_{e}^{1 / 2}\left(1-\left(1-s_{e}^{1 / m}\right)^{m}\right)^{1 / 2} \\
& k_{r n w p}=\left(1-s_{e}\right)^{1 / 3}\left(1-s_{e}^{1 / m}\right)^{2 m}
\end{aligned}
$$

\subsubsection{Thermal energy conservation} each phase, the interfacial heat transfer term in each equation is selected to be large enough relative to the 


$$
\begin{gathered}
\nabla \cdot\left(\varepsilon s_{\alpha} \rho_{\alpha} \mathbf{U}_{\alpha} e_{\alpha}-\varepsilon s_{\alpha}\left(\lambda_{\alpha}+C_{P} \frac{\mu_{T}}{\operatorname{Pr}_{T}}\right) \nabla T_{\alpha}\right)=\varepsilon s_{\alpha} \boldsymbol{\tau}_{\alpha}: \nabla \mathbf{U}_{\alpha}+S_{E \alpha}+Q_{\alpha} \\
\nabla \cdot\left((1-\varepsilon) \rho_{s} \mathbf{U}_{s} e_{s}-(1-\varepsilon) \lambda_{s} \nabla T_{s}\right)=S_{E s}+Q_{s}
\end{gathered}
$$

364 Here $S_{E \alpha}$ denotes external heat source and $Q_{\alpha}$ the interface heat transfer.

\subsubsection{Turbulence}

The modeling of the turbulence is done using a homogeneous formulation, where the same equation that is used for single phase flow is solved. The main difference lies in the use of phase volume averaged densities, viscosities and velocities.

\subsubsection{Boundary conditions}

In the modeling domain different types of boundary conditions are applied, in addition to the standard no-slip condition and wall-functions for turbulence.

\subsubsection{Mass}

At the manifold inlet, the mass flow of liquid water is specified as function of water stoichiometry and current density as follows:

$$
\dot{m}_{i n}=\frac{M_{w, H_{2} O} \lambda j A_{c}}{2 F}
$$

Here $\lambda$ is the stoichiometric factor, and $A_{c}$ is the cross-sectional area.

At the GDL-MPL interface a mass flux opening is specified. This opening reflects the flux of liquid and gas phase respectively being consumed and produced in the $\mathrm{CL}$ due to the electrochemical reactions:

$$
\begin{gathered}
\bar{m}_{l}=-\frac{M_{w, H_{2} O} j_{c}}{2 F} \\
\bar{m}_{g}=\frac{M_{w, O_{2}} j_{c}}{4 F}
\end{gathered}
$$

Here $\bar{m}$ denotes mass flux.

\subsubsection{Temperature}

In this work, an adiabatic temperature conditions is specified at all walls except the GDL-MPL interface:

$$
\nabla T \cdot \mathbf{n}=0
$$

Here $\mathbf{n}$ is a normal vector. At the GDL-MPL interface, the following heat flux is specified: 


$$
q=\left(V_{\text {cell }}-\frac{\Delta H^{\circ}}{n F}\right) I_{c e l l}
$$

387 At the outlet, the temperature is fixed. This means that the inlet temperature varies depending on the 388 operating conditions. By setting up an energy balance and assuming that heat only is removed through the gas and liquid phases, the inlet temperature can be calculated as function of outlet temperature, the heat generated during water electrolysis and the inlet mass flow.

$$
T_{\text {in }}=(1-\underbrace{\frac{1}{\lambda}}_{\approx 0}+\underbrace{\frac{\bar{m}_{g, o u t} A c_{g, p}}{\dot{m}_{l, i n} c_{l, p}}}_{\approx 0}) T_{\text {out }}-\frac{q A}{\dot{m}_{l, i n} c_{l, p}}
$$

Here $A$ is the cross-sectional area and $c_{p}$ is the specific heat capacity at constant pressure.

\subsubsection{Pressure}

At the outlet a static gauge pressure condition is specified:

$$
p_{\text {out }}=0
$$

At the GDL-channel interface the following boundary condition for the capillary pressure is implemented:

$$
\nabla p_{c}=0
$$

This condition is in good alignment with the fact that a constant particle diameter is assumed in the channel domain. According to the Young-Laplace equation, a constant diameter is equivalent to a constant capillary pressure assuming that the surface tension does not vary significantly with temperature:

$$
p_{c}=\frac{4 \sigma_{l g}}{d}=\text { Const }
$$

Consequently, the gradient of the capillary pressure within the channel domain has to be zero. It should be noted that the applied boundary condition for the capillary pressure is in contrary to the conventional applied condition of a fixed saturation or capillary pressure often found in literature. This condition is essentially neither mechanistic nor physically substantiated, and has therefore been subject to much debate in many modeling studies [37,38].

\subsection{Numerical Model}

The presented mathematical models are solved using the commercial CFD software, ANSYS CFX 15. In obtaining a solution, the coupled multiphase solver with a high resolution discretization scheme is used. The pressurevelocity coupling is modeled using a fourth order Rhie-Chow scheme. Moreover, a tri-linear pressure and 
velocity interpolation is set. In order to capture steep gradients in the volume fraction, the compressive interface capturing scheme for arbitrary meshes is activated. Here, a default slope limiter of 2 is specified.

\subsection{Data treatment}

To be able to evaluate the extent of maldistribution in a systematic manner, a weighted arithmetic mean and standard deviation are calculated. Essentially, these quantities allow for a direct comparison between the individual simulation conditions for both single- and two-phase flow models:

$$
\begin{gathered}
\sigma_{\varphi}=\sqrt{\frac{1}{N W} \sum_{j=1}^{N} w_{j}\left(\varphi_{j}-\mu_{\varphi}\right)^{2}} \\
\mu_{\varphi}=\frac{1}{N W} \sum_{j=1}^{N} \varphi_{j} w_{j} \\
W=\sum_{j=1}^{N} w_{j}
\end{gathered}
$$

Here $\sigma_{\varphi}$ is the weighted standard deviation, $\mu_{\varphi}$ is the weighted mean, $\varphi$ is the distributed variable, $N$ is the number of entities and $w_{j}$ is the weight of entity $j$.

The standard deviations of three different variables are investigated:

$$
\varphi \in\left\{\frac{\dot{m}_{l, i}}{L_{c}}, T_{l}, s_{g}\right\}
$$

Here $\dot{m}_{l, i}$ is the liquid mass flow rate of each channel, $L_{c}$ is the channel length, $T_{l, i}$ is the liquid phase temperature and $s_{g}$ is the gas volume fraction. The normalized mass flow is calculated on help-planes near the inlet and outlet as follows:

$$
\dot{m}_{i}=\int_{A_{i}} \rho \mathbf{U} \cdot \mathbf{n} d A
$$

Here $\mathbf{n}$ is the normal vector of the help plane and $\dot{m}_{i n}$ is the mass flow at the inlet of the manifold. It should be noted that the channel mass flow is divided by channel length to account for the difference in cross-sectional surface area, and thus the amount of produced gas and heat. The active area each channel is in contact with is approximately proportional to the channel length.

While a mass flow has to be measured across a surface and hence discretely, the temperature and gas volume fraction are continuous field quantities that are locally defined for each control volume. Because each control volume may differ in size (i.e. volume or mass), a specific weight applies to each variable: 
436 Here $m_{l}$ is the liquid mass in each control volume and $V$ is the control volume.

\section{$437 \quad 3 \quad$ Results and Discussion}

438 The results section is split into two parts; a comparison between the single- and two-phase models under nominal conditions and a parameter variation relative to nominal conditions. The selected parameters under nominal conditions are depicted in Table 2. It should particularly be noted that the mean gas particle diameter, which is used in the applied two-phase flow model for calculating interfacial transport phenomena in the channel flow field, is somewhat unknown. In this study, the gas particle diameter is therefore specified to be equal to the characteristic pore diameter. This seems to be a reasonable starting point as it is the largest characteristic particle size exiting the pores. The actual size is difficult to predict because of interfacial forces, turbulent mixing as well as particle coalescence and break-up.

446 In the parametric study two factors are investigated; the effect of stoichiometry for both the single- and twophase models, and the effect of particle diameter for two-phase flow model.

Table 2: Nominal operation conditions

\begin{tabular}{|l|l|l|l|}
\hline Parameter & Symbol & Value & Unit \\
\hline Temperature & $T$ & 343 & $\mathrm{~K}$ \\
\hline Permeability & $\kappa$ & $2.25 \times 10^{-11}$ & $\mathrm{~m}^{2}$ \\
\hline Porosity & $\mathcal{1}$ & 0.82 & - \\
\hline GDL thickness & $L_{T}$ & 300 & $\mu \mathrm{m}$ \\
\hline Water stoichiometry & $\lambda$ & 350 & - \\
\hline Cathode pressure & $P_{\text {cat }}$ & 6 & $\mathrm{Bar}$ \\
\hline Anode pressure & $P_{\text {an }}$ & 100 & \\
\hline Cell voltage & $V_{\text {cell }}$ & 1.9 & $\mathrm{~V}$ \\
\hline Cell current density & $j_{\text {cell }}$ & 1.0 & $\mathrm{~A}$ \\
\hline Average gas Reynolds number & $\mathrm{Re}_{\text {gas }}$ & 3000 & \\
\hline Average liquid Reynolds number & $\operatorname{Re}_{\text {liq }}$ & 10000 & \\
\hline Particle diameter in channels & $D_{\text {particle }}$ & 20 & $\mu \mathrm{m}$ \\
\hline Characteristic pore diameter [39] & $D_{\text {pore }}=4 \sqrt{\kappa / \varepsilon}$ & 20 & $\mathrm{Mm}$ \\
\hline Genuchten model coefficients & $m, n, p_{c b}$ & $0.6489,2.848,8200$ &.-- -. Pa \\
\hline
\end{tabular}


In Figure 3-1, the distribution of liquid phase mass flow rate per channel length is depicted. For comparison both the distributions predicted by the single- and two-phase models have been plotted. At a first glans, both models seem to predict the same trend. The highest values are found in the two shortest channels. From here on and towards the longest channel in the center of the flow field, the mass flow rate per channel length then decreases. It is worth noting that reversed flow does not occur and hence no local mass starvation occurs. Moreover, the interdigitated flow field shows significantly less maldistribution than what is observed in the modeling study by Nie and Chen [30] on parallel-straight channel for PEMEC.

A comparison between the two predicted distributions reveals that the added gas phase changes the distribution slightly. Between channels 2 and 8 it appears that the distribution becomes less uniform. This suggests that the added gas phase hinders the transport of the liquid phase across the flow field. One possible explanation could be that the added gas lowers the relative permeability, which then increases the liquid phase resistance through the porous medium. This shift in the balance between the effect of the channel and porous medium resistance could cause the liquid phase to distribute differently [40].

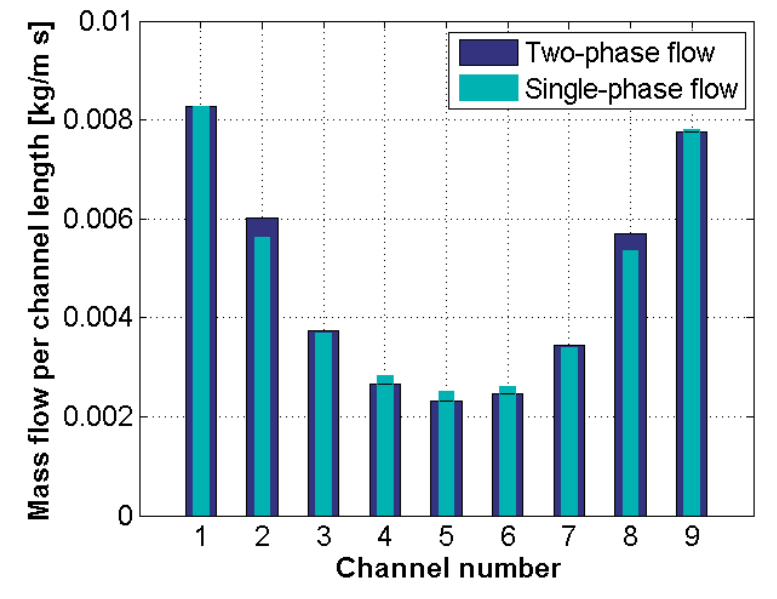

Figure 3-1: Bar graph of the mass flow rates per channel length for each individual outlet channel

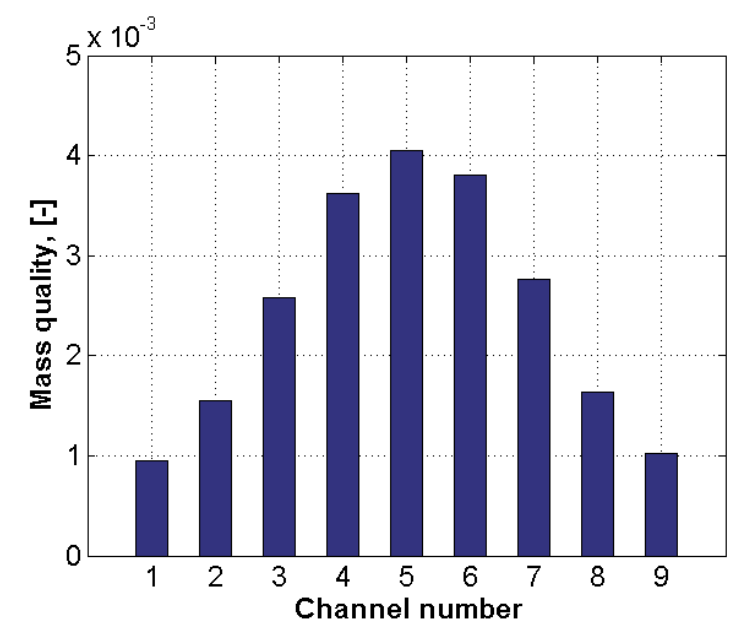

Figure 3-2: Bar graph of the mass quality distribution among the outlet channels

An examination of the mass quality in Figure 3-2 shows a parabolic distribution between the channels. In the shortest channels, a significant higher amount of the liquid phase is being transported relative to the amount of gas phase. Hence, a much higher local average water stoichiometry can be seen, since they are directly proportional. Moreover, this further implies that a lower gas volume fraction can be expected here.

From these preliminary observations, it could be hypothesized that an improved mass flow distribution could be obtained by shortening the distance between the longest channels and/or expanding the distance between the shortest channels. This would increase the resistance between the shortest channels relative to resistance between the longest channels and hence force more flow through the longest channels at the center of the 
473 flow field. Meanwhile, the question remains how large these differences should be and if they result in a

474 critical land area thickness, which cannot support the mechanical compression exerted from the cathode.

475 As shown in a preliminary study of the single-phase flow distribution in a circular-planar, interdigitated flow 476 field by Olesen and Kær [40], maldistribution between channels is strongly dependent on the permeability of 477 the GDL. For the geometry studied in this work, a transition point in the dependence of the viscous 478 permeability was identified. Below this transition point only minor improvements are seen in the uniformity of 479 the water distribution, whereas above a significant increase in channel maldistribution results with increasing 480 permeability.

481 For the Ti-felt considered in this work, values slightly higher than this transition point are seen. This implies that 482 the distribution between channels should mainly be dominated by the transport losses within the GDL. Since 483 the transport within the GDL follows Darcy's law, this further implies that the overall mass flow maldistribution 484 likewise does so. Provided that the mass flow between each pair of interdigitated channels could be viewed as 485 a one-dimensional transport process, the mass flow rate would be inversely proportional to the land area 486 width, or conversely on a mass flow rate per channel length basis, inversely proportional to the land area size. 487 In view of this, a more uniform mass flow distribution would therefore be obtainable if all land areas had the 488 same in-plane cross sectional area. However, this requires that single-phase like conditions prevail for the 489 liquid phase. In other words, the presence of the gas phase should not significantly alter the distribution of the 490 liquid phase. Interestingly, this seems to be the case under the nominal conditions from the mass flow rate 491 distribution in Figure 3-1.

492 Nonetheless, the importance of two-phase flow phenomena cannot be neglected in all cases. The higher the 493 amount of gas is relative to the land area size and liquid phase mass flow rate, the more the distribution of 494 water is affected by capillary pressure action and relative permeability changes, because of the dependence on 495 gas volume fraction. For much wider land areas it could therefore be imagined that a higher gas volume 496 fraction in the direction of the flow would be obtained. Under these circumstances, a much larger resistance to 497 498 499 500 water transport would be seen due to a decrease in relative permeability of the liquid phase. It is therefore not fully clear where the optimum lies, since equal land area sizes would make some areas much wider and therefore impose some differences in transport resistance. Still, an improved distribution should be obtainable by approaching more equal land area sizes.

501 To verify the validity of this line of reasoning, the ratio of land areas for the present design could be calculated. 502 Between the shortest channels the land area is $1.069 \mathrm{e}-4 \mathrm{~m}^{2}$, and between the longest channels the land area is $5034.236 \mathrm{e}-4 \mathrm{~m}^{2}$. Indeed, this gives a ratio of land areas of 3.96, which approximately equals the observed ratio of 504 mass flow rates per channel length for the longest and shortest channels, as can be seen from Figure 3-1. In 505 order to make the land areas equal, the average width between the longest channels would have to be 506 reduced to $1.3 \mathrm{~mm}$ from the original $5 \mathrm{~mm}$. This further means that additional interdigitated channels would 507 have to be added to account for the decreased land area width.

508 In order to identify the minimum land area width, which can support the imposed mechanical stress, the 509 compressive strength of the BP can be evaluated. This parameter essentially determines the materials ability to 
510 withstand deformation due to compression. For a high pressure PEM electrolysis cell, a suitable material could 511 be vinyl ester. This polymeric material has a compressive strength of $76 \mathrm{MPa}$ [41]. Even for a flow field open 512 ratio of 0.5 , which corresponds to a land area width of equal size as the channel width, the material could 513 withstand a cathode operating pressure of up to 380 bars. If a safety factor of 1.5 is included the number 514 reduces to 253 bars. Hence, from a material mechanical point of view, it seems feasible to decrease the land 515 area for example by lowering the average distance between the longest channels. Even for land area 516 thicknesses of down to $1 \mathrm{~mm}$, which corresponds to the channel width, the mechanical strength would be 517 enough to sustain the intended conditions of up to 200 bars.

518 It should be noted that the selected value for the safety factor reflects a certain risk of statistical failure and 519 that stress concentrations may form near corners which could cause fractures. Further analysis of filling radii 520 and land area heights would however require a detailed finite element analysis.

\section{$521 \quad 3.1 .2$ Volume Fraction}

522 In Figure 3-3 and Figure 3-4, the in-plane distribution of gas volume fraction is depicted at two different 523 locations. In Figure 3-3, the gas volume fraction inside the channel structure is shown. At the inlet it is seen 524 how only the liquid phase enters the anode and distributes across the inlet manifold. In each inlet channel, a 525 small amount of gas volume fraction is visible. Because the liquid phase is convectively transported through the 526 GDL, the gas phase is pushed towards the outlet channels. However, a small amount of gas flows out of the 527 GDL and into the inlet channels and then re-enters the GDL further down the channel.

528 Between the outlet channels, large variations in the resulting gas volume fraction can be observed. In the 529 shortest channels, regions with low gas volume fraction are visible; from here and towards the longest 530 channels, the amount of gas volume fraction then gradually increases. It should be noted that this distribution 531 is in agreement with the observed phase mass flow ratio distribution. In the outlet manifold, the two-phase 532 flow streams from each individual outlet channel mix together. At the outlet, this results in a final gas volume 533 fraction of 0.26 . 


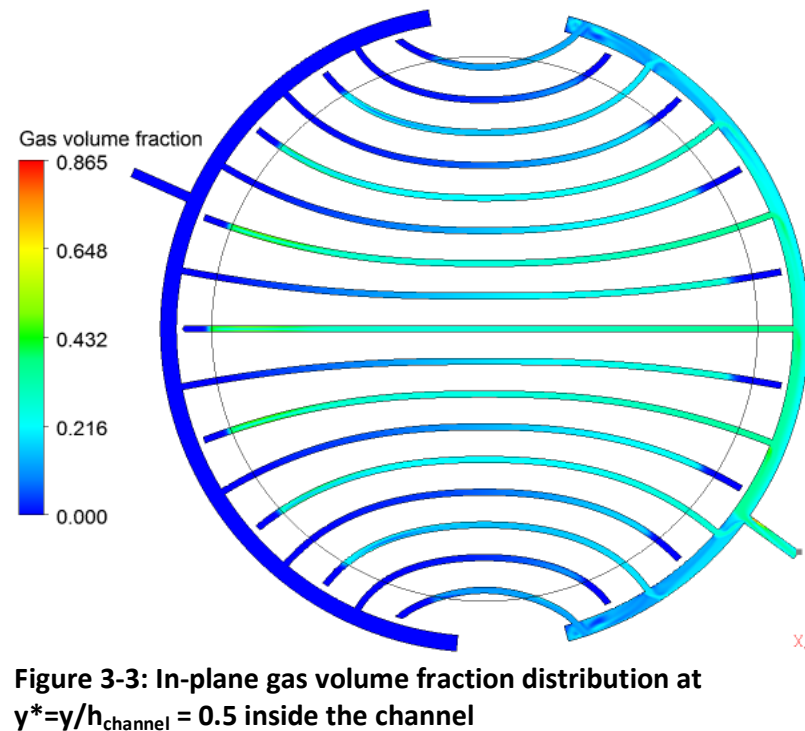

$y^{*}=y / h_{\text {channel }}=0.5$ inside the channel

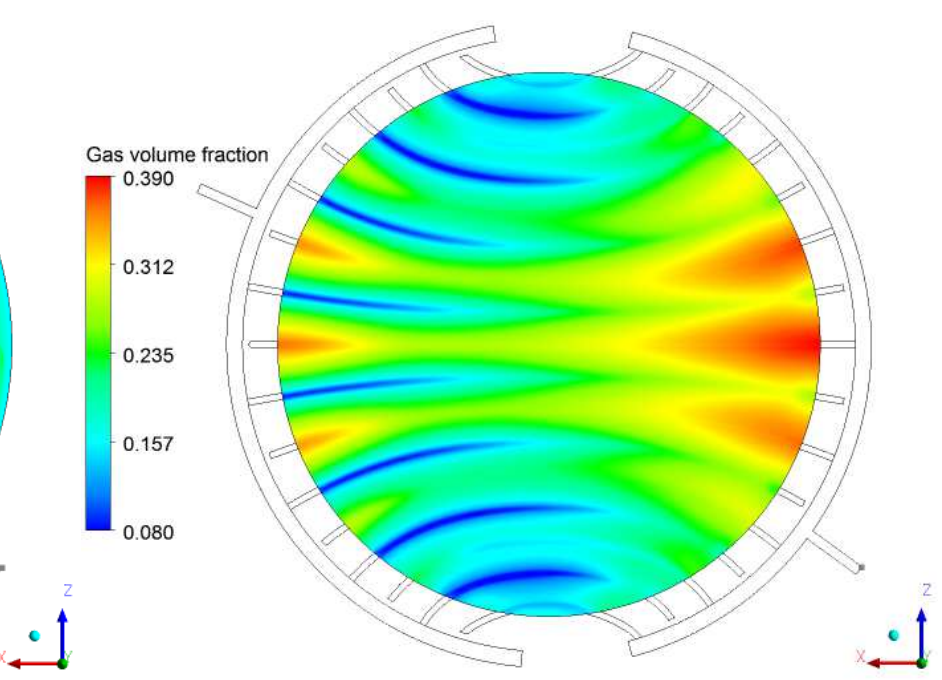

Figure 3-4: In-plane gas volume fraction distribution at $y^{*}=y / t_{G D L}$ $=0.5$ inside the GDL

In Figure 3-4, the gas volume fraction distribution inside the GDL is portrayed. While regions of low gas volume fraction form underneath the inlet channels, the opposite is seen for the outlet channels. Along the outlet channels a skewed, parabolic distribution of the gas volume fraction forms. At both ends of the channels, the gas volume fraction is high and then gradually decreases along the channel length. The highest amount of gas volume fraction is seen near the end of outlet channels.

Further variation in the gas volume fraction can be identified between each channel. Underneath the shortest channels, regions of lower gas volume fraction are visible. This distribution coincides with the distribution found above in the outlet channels. Hence, the gas volume fractions inside the GDL and above are directly coupled. This is an effect that would not have been seen, if a constant gas volume fraction or capillary pressure would have been specified as a boundary condition.

\subsubsection{Velocity}

The in-plane distribution of phase velocity within the GDL is depicted in Figure 3-5 and Figure 3-6 for the liquid and gas phase, respectively. Throughout Figure 3-5, large variations can be observed in the liquid phase velocity; particularly between the shortest and longest channels. Along the channel length, a parabolic distribution can furthermore be seen. The lowest liquid phase velocity is located at the center and then gradually increases along the channel length in both directions.

A quite different velocity distribution is seen in Figure 3-6 for the gas phase. Clearly, the dominating mechanisms behind the movement of gas and liquid are different. While the variations in gas phase velocity under nominal conditions predominantly are caused by capillary pressure and turbulent dispersion forces, the variations in liquid phase velocity appear mainly to be due to the circular shape of the flow field and the differences in land to channel area. 
When taking a closer look at the gas phase velocity distribution, narrow high velocity zones become apparent near the inlet channels. These zones are most prominent near the start of channel and then gradual fade out along the channel length. It turns out that these zones indicate where the gas phase flows into the inlet channels and thus opposite the liquid phase flow. Further down the channel length, the gas phase then reenters the GDL. This redistribution along the inlet channel length is what causes the observed skewed, parabolic distribution in gas volume fraction as well as the higher gas velocities downstream of the inlet channels. This phenomenon is initiated by the turbulent dispersion force and reinforced by the fact that the gas phase relative permeability lowers at higher gas volume fractions. This in turn means that the gas phase easier can flow through the GDL downstream of the channel.

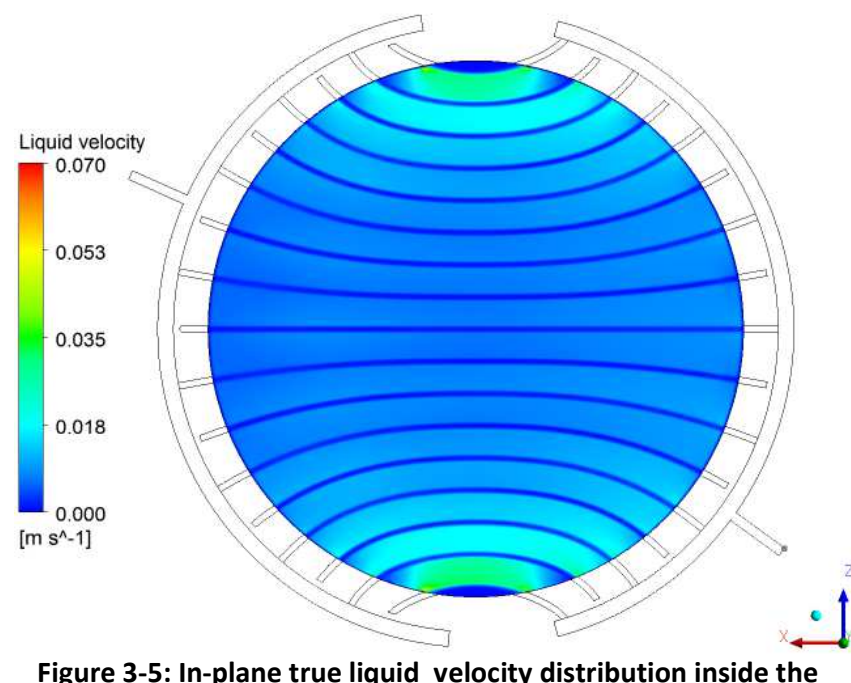

Figure 3-5: In-plane true liquid velocity distribution inside the $\mathrm{GDL}$ at $\mathrm{y}^{*}=\mathrm{y} / \mathrm{t}_{\mathrm{GDL}}=0.5$

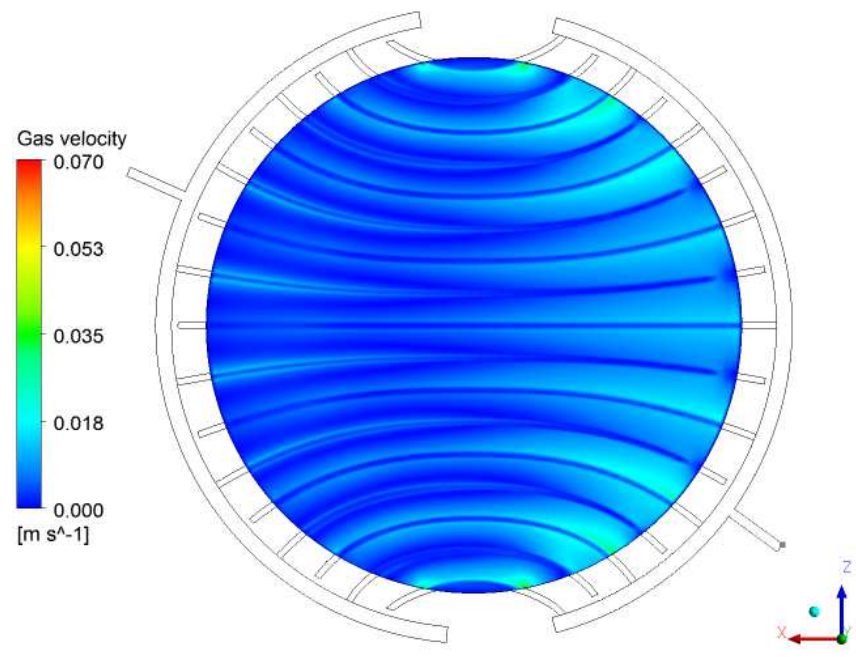

Figure 3-6: In-plane true gas velocity distribution inside the GDL at $\mathrm{y}^{*}=\mathrm{y} / \mathrm{t}_{\mathrm{GDL}}=0.5$

\subsubsection{Temperature}

In Figure 3-7 and Figure 3-8, the predicted in-plane liquid phase temperature distributions of the interdigitated channel structure and GDL are illustrated, respectively. At the manifold inlet in Figure 3-7, the liquid phase enters at a temperature of approximately $340 \mathrm{~K}$. After the GDL, the resulting two-phase flow streams mix and the combined flow leaves the manifold outlet at a temperature of $343.15 \mathrm{~K}$, as specified. Within the channels, the highest temperature is reached in the longest channel. Here the temperature becomes $345 \mathrm{~K}$, approximately $2 \mathrm{~K}$ higher than the outlet temperature. From the longest to the shortest outlet channel, a gradual decrease in temperature is visible. This variation is partly a reflection of the difference in active surface area between inlet and outlet channels, and partly due to the difference in mass flow and hence thermal capacity of the flow. 


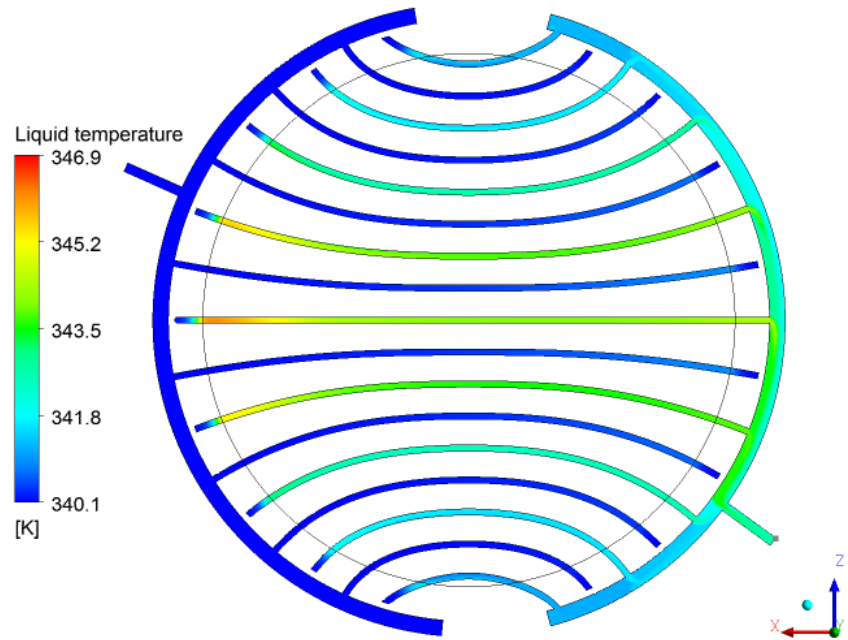

Figure 3-7: In-plane temperature distribution inside channels at $\mathrm{y}^{*}=\mathrm{y} / \mathrm{t}_{\mathrm{chan}}=0.5$, under nominal conditions

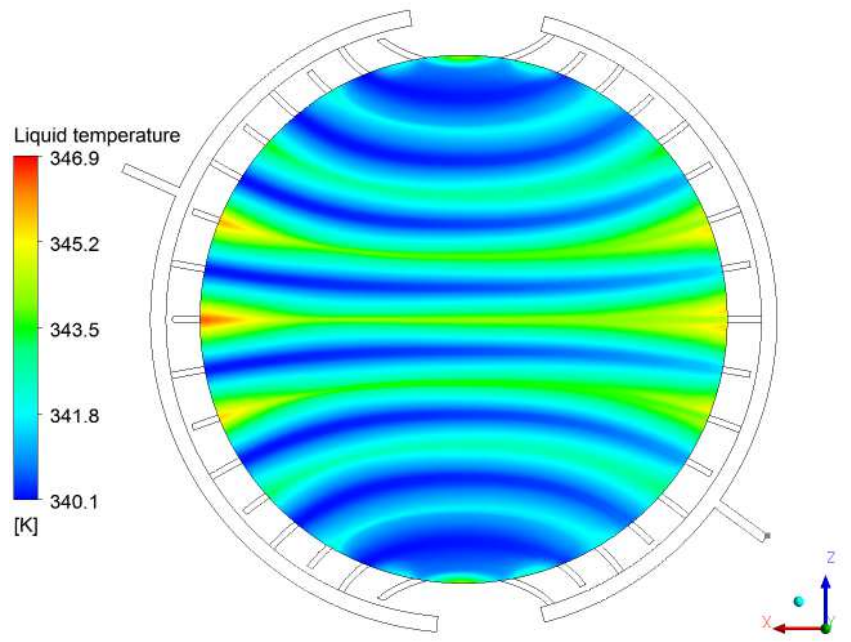

Figure 3-8: In-plane temperature distribution inside the GDL at $\mathrm{y}^{*}=\mathrm{y} / \mathrm{t}_{\mathrm{GDL}}=0.5$, under nominal conditions

Inside the GDL, as shown in Figure 3-8, the same trend in the temperature distribution can be seen as within the channels; the highest temperature is found underneath the longest channels. Between inlet and outlet channel a large temperature gradient is visible. A further variation can be identified along the channel length. This seems to be in accordance with the observed velocity and gas volume fraction distributions. Both a high velocity and a low gas volume fraction mean better cooling. The more liquid phase, the higher the thermal capacity and the better the effective heat conduction becomes. Consequently, the highest temperatures are to be expected where the liquid velocity is lowest and the gas volume fraction the highest relative to amount of heat being dissipated.

\subsection{Effect of Stoichiometry}

\subsubsection{Channel mass flow}

The standard deviation in liquid mass flow per channel length as function of water stoichiometry is depicted in Figure 3-9. For the single- and two-phase simulation cases, the same trend appears. As the water stoichiometry increases, correspondingly does the standard deviation. Below a water stoichiometry of 350, the standard deviation increases due to the presence of the gas phase when compared with the single-phase case, whereas above the two-phase flow decreases the standard deviation compared with single-phase conditions. With this in mind, it would seem that the gas phase hinders distribution of water below a water stoichiometry of 350, but improves it slightly above. 


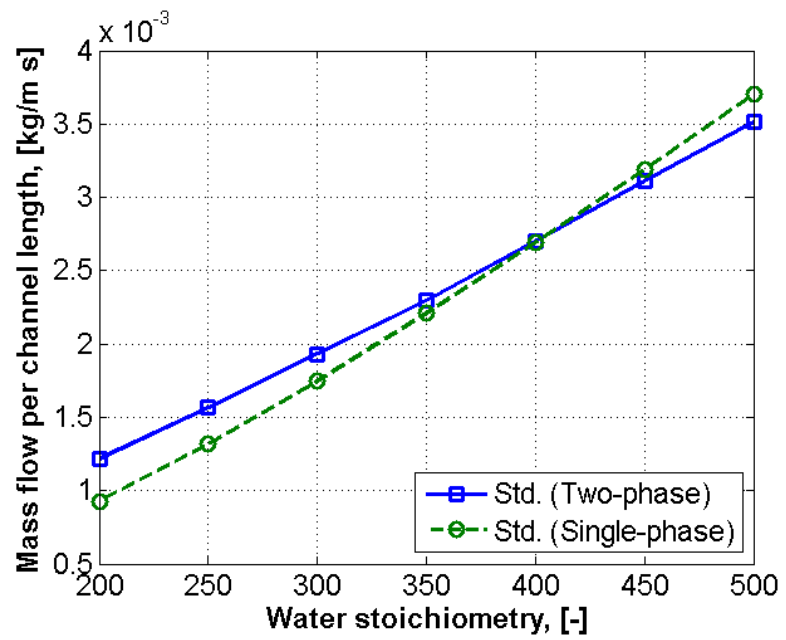

Figure 3-9: Standard deviation in liquid mass flow rate per channel length for outlet channels.

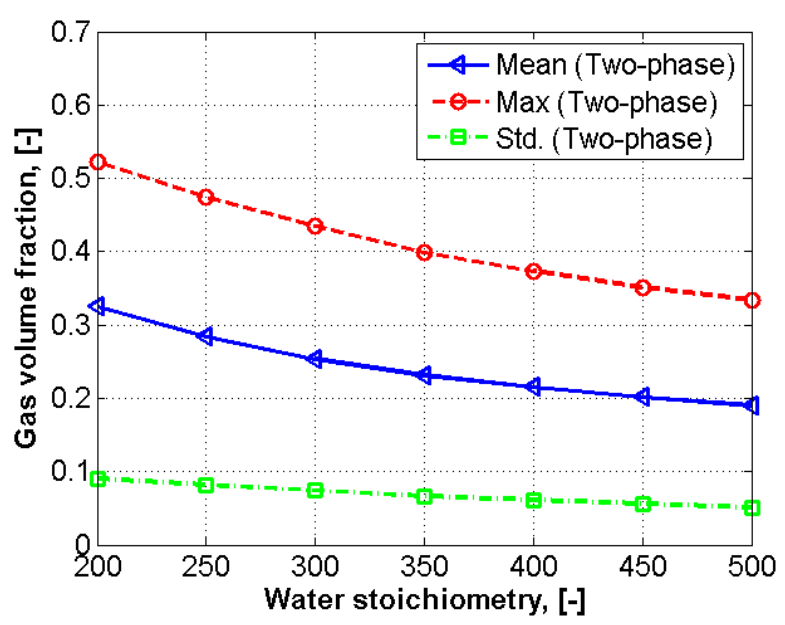

Figure 3-10: Mean, maximum and standard deviation in gas volume fraction throughout the GDL.
591

592

593

594

595

596

597

598

599

600

601

602

603

604

605

606

607

608

609

610

611

612

613

\subsubsection{Gas volume fraction}

In Figure 3-10, the mean, maximum and standard deviation in gas volume fraction are depicted for the GDL.

For each statistical parameter, the same inversely proportional dependence on water stoichiometry is seen. In particular, it is noticeable that the standard deviation is nearly halved in the simulated range of water stoichiometry. This is a clear indication that the gas volume fraction distributes more uniformly with increasing water stoichiometry. However, the extent of this apparent effect also seems to diminish with increasing water stoichiometry. Consequently, a substantial increase in water stoichiometry is necessary to further lower the standard deviation in gas volume fraction above a water stoichiometry of 500.

It can further be noticed that the gas volume fraction exceeds a maximum value of 0.5 at a water stoichiometry below 350 . Hence, low stoichiometry operation will cause a significantly increased pressure loss relative to single-phase conditions as well as poorer heat removal.

\subsubsection{Temperature}

From the temperature variation shown in Figure 3-11, a decrease in maximum temperature is seen as function of water stoichiometry. This is comparatively the same tendency as for the gas volume fraction. With this in mind, it appears that the presence of the gas phase significantly increases the formation of hotspots. From the single-phase simulation it appears that the water stoichiometry in itself results in an increase in maximum temperature due to a non-uniform mass flow distribution. Meanwhile, this is much more pronounced in the case of the two-phase flow.

Interestingly, the opposite behavior is seen in the mean temperature; as the water stoichiometry increases, so does to the average temperature. Although this might seem odd at first sight, it must be remembered that an increasing mass flow reduces the required temperature difference needed for cooling. Hence, the average temperature has to increase with water stoichiometry. In fact, it will asymptotically approach the outlet temperature. What furthermore may be surprising is that the mean temperature is nearly equal for single- and 
two-phase flow. Despite the formation of hotspots, the overall impact on the mass-averaged temperature is

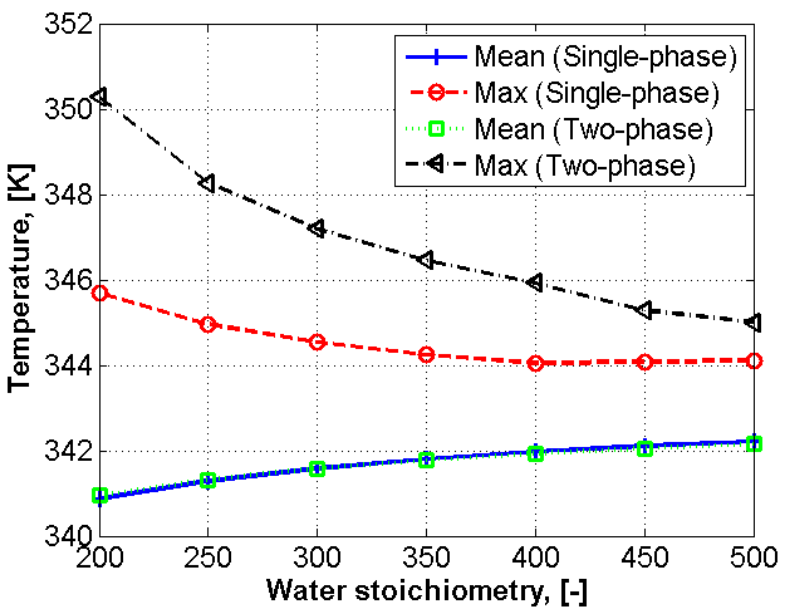

Figure 3-11: The mean and maximum temperatures throughout the GDL, as predicted by the single- and two-phase models

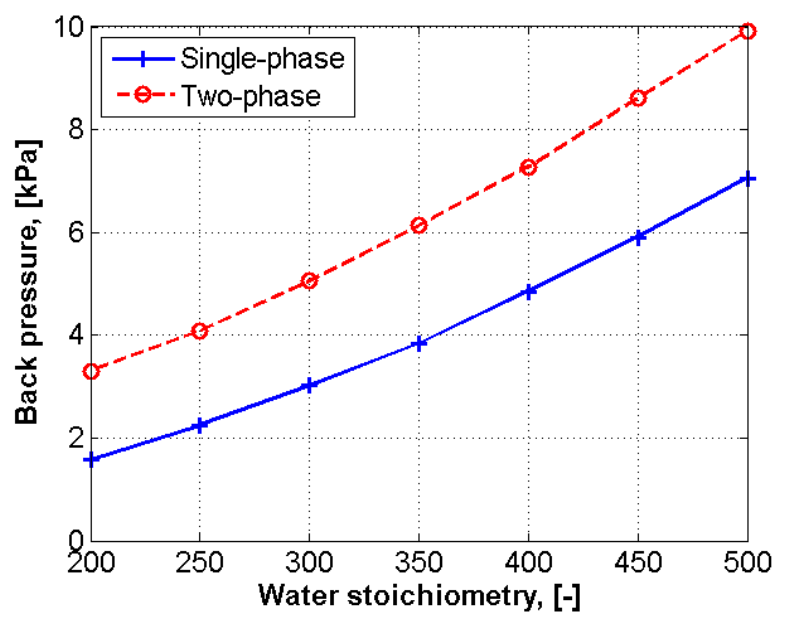

Figure 3-12: Back pressure as a function of water stoichiometry for single- and two-phase flow

Finally, it should be noted that the simplification of a uniformly distributed current density, inherently is affected by the maldistribution of temperature and not to mention two-phase flow. Areas where a high temperature is seen, an equivalent high current density would be produced for the same applied voltage difference. The impact of the maldistribution on current density can only be revealed fully by modeling a whole cell. Meanwhile, the standard deviation in temperature inside the GDL is fairly low, which would suggests that overall the current density would be fairly uniform.

\subsubsection{Back pressure}

The back pressure as a function of water stoichiometry is shown in Figure 3-12. While the required differential pressure for the single-phase model increases from 1.58 to $7.06 \mathrm{kPa}$, the differential pressure for the twophase model increases from 3.3 to $9.92 \mathrm{kPa}$. At low water stoichiometry, roughly a factor of two in difference can be seen between single- and two-phase flows. As the water stoichiometry increases, this difference increases slightly. However, the extent is significantly less than the absolute increase in both the single- and two-phase pressures. This corresponds well to the fact that the mean gas volume fraction decreases in the GDL and hence less gas hinders liquid phase transport.

\subsection{Particle diameter}

\subsubsection{Channel mass flow}

The effect of particle diameter on the standard deviation in mass flow per channel length is depicted in Figure 3-13. From the graph it is apparent that the mass flow distribution is sensitive to particle diameter and as such the forces related to the particle size. As the particle size grows, mass flow maldistribution increases relative to single-phase conditions. The increased maldistribution can to a high extent be attributed to the change in drag 
force. The larger the particle diameter, the slower the gas bubbles move relative to the liquid phase. In turn,

637 this effect causes a higher gas phase hold-up.

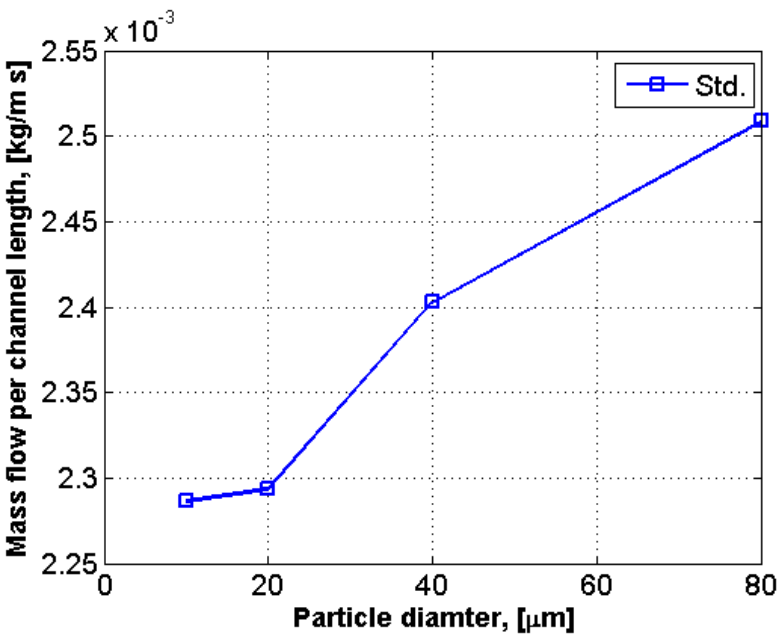

Figure 3-13: Standard deviation in mass flow per channel length as function of particle diameter

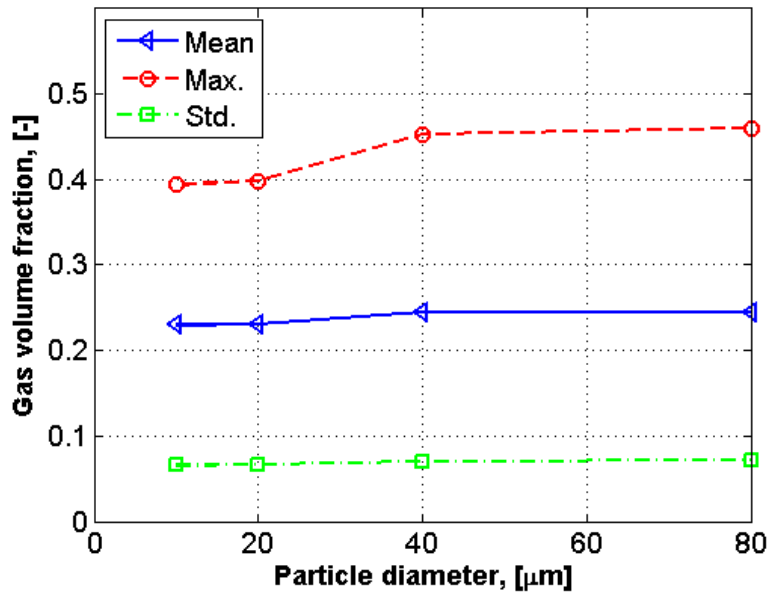

Figure 3-14: Mean, maximum and standard deviation in gas volume fraction inside the GDL as function of particle diameter

\subsubsection{Gas volume fraction}

The change in gas volume fraction as function particle diameter is shown in Figure 3-14. While the mean and standard deviation show a minor dependence, a considerable impact is observed in the maximum gas volume fraction. Above a particle diameter of 40 micrometer, an excessive amount of gas forms near the beginning of the outlet channels, where the land area is the widest and the channel flow lowest. This build-up of gas in turn lowers the rate of heat removal, because of the lowered liquid mass flow rate and decreased heat conductivity.

\subsubsection{Temperature}

In Figure 3-15, the impact on the temperature distribution is shown. As expected from the gas volume fraction, a substantial impact is likewise seen on the maximum temperature. The temperature increases with nearly $2^{\circ} \mathrm{C}$ when doubling the particle size from 20 to 40 micrometer. Interestingly, the location of this temperature increase coincides with the maximum gas volume fraction. At the same time as this large increase in maximum temperature is seen, a negligible effect on the mean temperature is found. This means that the effect is restricted to fairly local areas.

The observed large impact of particle diameter on temperature underlines the importance of accurately determining it. As such particle diameter does not significantly impact the average values of the temperature or gas volume fraction; hence it would, to some extent, make sense only to determine an appropriate average size. Else, the effect of particle coalescence and break-up could be accounted for using a multiple size group model. In this framework, a population balance is formulated which keeps track of the particle size distribution. 


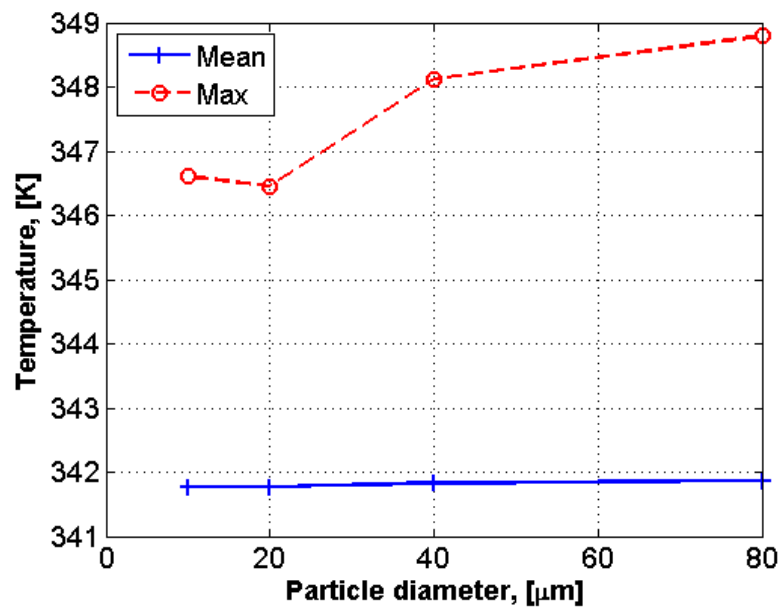

Figure 3-15: Mean and maximum temperature inside the GDL as a function of particle diameter.

\section{Conclusion}

In the present work, the flow and heat maldistribution in a circular-planar, interdigitated, anode flow field of a high pressure PEM electrolysis cell was studied. For this purpose, a comprehensive computational fluid dynamics model of the gas-liquid, two-phase flow was developed. In order to clearly identify the effect of twophase flow and geometry, a single-phase model was solved in addition as a reference.

From the obtained simulation results, the following conclusion can be drawn:

- The investigated design of the circular-planar, interdigitated flow field causes flow maldistribution. Although the extent increases as function of water stoichiometry, no mass transport limitation or reversed flow is seen.

- At a low water stoichiometry and under nominal conditions, the maldistribution in the flow of the liquid phase is adversely affected by the presence of the gas phase. Relative to single-phase conditions, this leads to an excessive formation of hotspots. A water stoichiometry above 350 at a current density of $1 \mathrm{~A} / \mathrm{cm}^{2}$ is necessary to avoid that the difference between maximum and mean temperature exceeds $4^{\circ} \mathrm{C}$.

- It is found that the extent of mass flow maldistribution can be reduced by approaching equal in-plane cross sectional land area sizes. This means that the land area width between the longest channels most be narrower than the width between the shortest channels. Indeed, if the overall mass flow maldistribution is dominated by the pressure losses within the GDL due to a low permeability, a more uniform distribution should be seen. However, it should be noted that the exact deviation from equal land areas depends on the extent of capillary pressure action and relative permeability of the GDL in question. 
- For BP plates made from vinyl ester and under nominal conditions, the suggested geometrical changes do not lead to a critical land area width, which cannot sustain the compression forces exerted by cathode operating pressure.

- To minimize the formation of hotspots where the land areas are the widest, the extent of channel bending should be reduced.

To validate model predictions different experimental approaches can be taken. The simplest being a measurement of the anode back pressure, similarly as in the study by Nie and Chen [6]. However, such a type of validation does not give any details about the two-phase flow distribution inside channels or within the GDL; essentially, it only gives a lumped effect. A better approach would be to use a transparent BP similarly as done by Su et al. [18]. This approach allows for the use of direct imagining techniques, which enable direct bubble tracking through the use of edge detection algorithms by means of MATLAB or NI Vision. Furthermore, this techniques makes it is possible to determine of the bubble size distribution within a confined area of the channel flow field. In addition, a thermographic camera could be added to determine the temperature distribution within the flow field and highlight hotspot formation. Meanwhile, to get the two-phase distribution within the GDL, neutron radiography is necessary. This technique has among others been applied by Owejan et al. [25].

In our future work, we intend to construct a cell with a transparent BP and then determine the bubble size distribution, track gas particles as well as measure the temperature distribution using a thermographic camera. Furthermore, the proposed improvements to the flow field will be implemented and tested in an operating electrolysis cell. The obtained results will then be compared to the previous design and potential new design improvements could further be proposed.

In regard to modeling, our future work will also include the application of a multiple size group model that takes particle coalescence and breakup into account. The implementation of such a model can be validated using the proposed measurement of the particle size distribution using a direct imagining technique. Furthermore, phase change will be included for studies at low anode pressures. Similarly, the presence of the bipolar plate will be added to improve model predictions of cooling phenomena.

\section{Acknowledgement}

This work was partially supported by the Danish Energy Technology Development and Demonstration program EUDP through the HyProvide project, and by the Innovation Fund Denmark through the e-STORE project. The authors would in addition like to thank the members of the Fuel Cells and Battery Systems Research Group at the Department of Energy Technology for their input.

\section{References}

[1] Hedegaard K, Ravn H, Juul N, Meibom P. Effects of electric vehicles on power systems in Northern Europe. Energy 2012;48:356-68. doi:10.1016/j.energy.2012.06.012. 
[2] Gutiérrez-Martín F, Guerrero-Hernández I. Balancing the grid loads by large scale integration of hydrogen technologies: The case of the Spanish power system. Int J Hydrogen Energy 2012;37:1151-61. doi:10.1016/j.ijhydene.2011.09.116.

[3] Pickard WF, Shen AQ, Hansing NJ. Parking the power: Strategies and physical limitations for bulk energy storage in supply-demand matching on a grid whose input power is provided by intermittent sources. Renew Sustain Energy Rev 2009;13:1934-45. doi:10.1016/j.rser.2009.03.002.

[4] Carmo M, Fritz DL, Mergel J, Stolten D. A comprehensive review on PEM water electrolysis. Int J Hydrogen Energy 2013;38:4901-34. doi:10.1016/j.ijhydene.2013.01.151.

[5] Zeng K, Zhang D. Recent progress in alkaline water electrolysis for hydrogen production and applications. Prog Energy Combust Sci 2010;36:307-26. doi:10.1016/j.pecs.2009.11.002.

[6] Onda K, Kyakuno T, Hattori K, Ito K. Prediction of production power for high-pressure hydrogen by highpressure water electrolysis. J Power Sources 2004;132:64-70. doi:10.1016/j.jpowsour.2004.01.046.

[7] Bensmann B, Hanke-Rauschenbach R, Peña Arias IK, Sundmacher K. Energetic evaluation of high pressure PEM electrolyzer systems for intermediate storage of renewable energies. Electrochim Acta 2013;110:570-80. doi:10.1016/j.electacta.2013.05.102.

[8] O’Hayre R, Cha SW, Colella W, Prinz FB. Fuel Cell Fundamentals. 2nd ed. John Wiley \& Sons, Inc.; 2009.

[9] Li X, Sabir I. Review of bipolar plates in PEM fuel cells: Flow-field designs. Int J Hydrogen Energy 2005;30:359-71. doi:10.1016/j.ijhydene.2004.09.019.

[10] Li H, Tang $Y$, Wang $Z$, Shi Z, Wu S, Song $D$, et al. A review of water flooding issues in the proton exchange membrane fuel cell. J Power Sources 2008;178:103-17. doi:10.1016/j.jpowsour.2007.12.068.

[11] Nguyen T V. A Gas Distributor Design for Proton-Exchange-Membrane Fuel Cells. J Electrochem Soc 1996;143:L103. doi:10.1149/1.1836666.

[12] Wang X-D, Duan Y-Y, Yan W-M, Peng X-F. Effects of flow channel geometry on cell performance for PEM fuel cells with parallel and interdigitated flow fields. Electrochim Acta 2008;53:5334-43. doi:10.1016/j.electacta.2008.02.095.

[13] Yan W-M, Mei S-C, Soong C-Y, Liu Z-S, Song D. Experimental study on the performance of PEM fuel cells with interdigitated flow channels. J Power Sources 2006;160:116-22. doi:10.1016/j.jpowsour.2006.01.063.

[14] Wang L, Liu H. Performance studies of PEM fuel cells with interdigitated flow fields. J Power Sources 2004;134:185-96. doi:10.1016/j.jpowsour.2004.03.055. 
[15] Hu G, Fan J, Chen S, Liu Y, Cen K. Three-dimensional numerical analysis of proton exchange membrane fuel cells (PEMFCs) with conventional and interdigitated flow fields. J Power Sources 2004;136:1-9. doi:10.1016/j.jpowsour.2004.05.010.

[16] Wang X-D, Duan Y-Y, Yan W-M, Weng F-B. Effect of humidity of reactants on the cell performance of PEM fuel cells with parallel and interdigitated flow field designs. J Power Sources 2008;176:247-58. doi:10.1016/j.jpowsour.2007.10.065.

[17] Natarajan D, Van Nguyen T. Three-dimensional effects of liquid water flooding in the cathode of a PEM fuel cell. J Power Sources 2003;115:66-80. doi:10.1016/S0378-7753(02)00624-9.

[18] SU A, WENG F, HSU C, CHEN Y. Studies on flooding in PEM fuel cell cathode channels. Int J Hydrogen Energy 2006;31:1031-9. doi:10.1016/j.ijhydene.2005.12.019.

[19] Berning T, Odgaard M, Kær SK. Water balance simulations of a polymer-electrolyte membrane fuel cell using a two-fluid model. J Power Sources 2011;196:6305-17. doi:DOI: 10.1016/j.jpowsour.2011.03.068.

[20] Yi JS, Nguyen T V. An Along-the-Channel Model for Proton Exchange Membrane Fuel Cells. J Electrochem Soc 1998;145:1149-59.

[21] Wood DL, Yi JS, Nguyen T V. Effect of direct liquid water injection and interdigitated flow field on the performance of proton exchange membrane fuel cells. Electrochim Acta 1998;43:3795-809. doi:10.1016/S0013-4686(98)00139-X.

[22] Yi JS, Nguyen T Van. Multicomponent Transport in Porous Electrodes of Proton Exchange Membrane Fuel Cells Using the Interdigitated Gas Distributors O F w I y K 1999;146:38-45.

[23] He W, Yi JS, Nguyen T Van. Two-Phase Flow Model of the Cathode of PEM Fuel Cells Using Interdigitated Flow Fields 2000;46:2053-64.

[24] Kazim a, Liu HT, Forges P. Modelling of performance of PEM fuel cells with conventional and interdigitated flow fields. J Appl Electrochem 1999:1409-16.

[25] Owejan JP, Trabold T a., Jacobson DL, Baker DR, Hussey DS, Arif M. In situ investigation of water transport in an operating PEM fuel cell using neutron radiography: Part 2 - Transient water accumulation in an interdigitated cathode flow field. Int J Heat Mass Transf 2006;49:4721-31. doi:10.1016/j.ijheatmasstransfer.2006.07.004.

[26] Yan W-M, Chen C-Y, Mei S-C, Soong C-Y, Chen F. Effects of operating conditions on cell performance of PEM fuel cells with conventional or interdigitated flow field. J Power Sources 2006;162:1157-64. doi:10.1016/j.jpowsour.2006.07.044.

[27] Berning T, Odgaard M, Kær SK. A study of multi-phase flow through the cathode side of an interdigitated flow field using a multi-fluid model. J Power Sources 2010;195:4842-52. doi:10.1016/j.jpowsour.2010.02.017. 
[28] Berning T, Kær SK. Low stoichiometry operation of a proton exchange membrane fuel cell employing the interdigitated flow field - A modeling study. Int J Hydrogen Energy 2012;37:8477-89.

[29] Ito H, Maeda T, Nakano a., Hasegawa Y, Yokoi N, Hwang CM, et al. Effect of flow regime of circulating water on a proton exchange membrane electrolyzer. Int J Hydrogen Energy 2010;35:9550-60. doi:10.1016/j.ijhydene.2010.06.103.

[30] Nie J, Chen Y. Numerical modeling of three-dimensional two-phase gas-liquid flow in the flow field plate of a PEM electrolysis cell. Int J Hydrogen Energy 2010;35:3183-97. doi:10.1016/j.ijhydene.2010.01.050.

[31] Olesen AC, Berning T, Kær SK. The Effect of Inhomogeneous Compression on Water Transport in the Cathode of a Proton Exchange Membrane Fuel Cell. J Fuel Cell Sci Technol 2012;9:031010. doi:10.1115/1.4006475.

[32] Tomadakis MM, Robertson TJ. Viscous Permeability of Random Fiber Structures: Comparison of Electrical and Diffusional Estimates with Experimental and Analytical Results. J Compos Mater 2005;39:163-88. doi:10.1177/0021998305046438.

[33] Menter FR. Two-equation eddy-viscosity turbulence models for engineering applications. AIAA J 1994;32:1598-605. doi:10.2514/3.12149.

[34] Sato Y, Sekoguchi K. Liquid velocity distribution in two-phase bubble flow. Int J Multiph Flow 1975;2:7995. doi:10.1016/0301-9322(75)90030-0.

[35] Gostick JT, Fowler MW, loannidis MA, Pritzker MD, Volfkovich YM, Sakars A. Capillary pressure and hydrophilic porosity in gas diffusion layers for polymer electrolyte fuel cells. J Power Sources 2006;156:375-87. doi:10.1016/j.jpowsour.2005.05.086.

[36] Gostick JT, Fowler MW, Pritzker MD, loannidis MA, Behra LM. In-plane and through-plane gas permeability of carbon fiber electrode backing layers. J Power Sources 2006;162:228-38. doi:DOI: 10.1016/j.jpowsour.2006.06.096.

[37] Berning T, Odgaard M, Kær SK. A Computational Analysis of Multiphase Flow Through PEMFC Cathode Porous Media Using the Multifluid Approach. J Electrochem Soc 2009;156:B1301-11.

[38] Gurau V, Thomas A. Zawodzinski J, J. Adin Mann J. Two-Phase Transport in PEM Fuel Cell Cathodes. J Fuel Cell Sci Technol 2008;5:21009. doi:10.1115/1.2821597.

[39] Nam JH, Kaviany M. Effective diffusivity and water-saturation distribution in single- and two-layer PEMFC diffusion medium. Int J Heat Mass Transf 2003;46:4595-611. doi:DOI: 10.1016/S00179310(03)00305-3.

[40] Olesen AC, Kær SK. Flow Maldistribution in the Anode of A Polymer Electrolyte Membrane Electrolysis Cell Employing Interdigitated Channels. Proc. 55th Conf. Simul. Model. (SIMS 55), Model. Simul. Optim. 21-22 Oct. 2014, Aalborg, Denmark, Linköping Electronic Conference Proceedings; 2014, p. 241-9. 


\section{List of Figures}

813 Figure 1: Anode planar-circular flow field

Figure 2: Titanium felt deformation strain, viscous permeability and volume porosity as function of deformation pressure

Figure 3: Polarization curve and heat generation of a PEMEC per unit area at $70 \mathrm{C}$, cathode pressure of $1.8 \mathrm{bar}$

[41] Inc. B. Data sheet for vinyl ester bipolar plate material - BMC 9402001. http://www.bulkmolding.com/datasheets/informational/bmc_940.pdf (accessed September 21, 2015).

Figure 4: Bar graph of the mass flow rates per channel length for each individual outlet channel

Figure 5: Bar graph of the mass quality distribution among the outlet channels

Figure 6: In-plane gas volume fraction distribution at $\mathrm{y}^{*}=\mathrm{y} / \mathrm{h}_{\text {channel }}=0.5$ inside the channel

Figure 7: In-plane gas volume fraction distribution at $\mathrm{y}^{*}=\mathrm{y} / \mathrm{t}_{\mathrm{GDL}}=0.5$ inside the GDL

Figure 8: In-plane true liquid velocity distribution inside the $G D L$ at $y^{*}=y / t_{G D L}=0.5$

Figure 9: In-plane true gas velocity distribution inside the $G D L$ at $\mathrm{y}^{*}=\mathrm{y} / \mathrm{t}_{\mathrm{GDL}}=0.5$

Figure 10: In-plane temperature distribution inside channels at $\mathrm{y}^{*}=\mathrm{y} / \mathrm{t}_{\mathrm{chan}}=0.5$, under nominal conditions

Figure 11: In-plane temperature distribution inside the $G D L$ at $\mathrm{y}^{*}=\mathrm{y} / \mathrm{t}_{\mathrm{GDL}}=0.5$, under nominal conditions

Figure 13: Standard deviation in liquid mass flow rate per channel length for outlet channels.

Figure 13: Mean, maximum and standard deviation in gas volume fraction throughout the GDL.

Figure 14: The mean and maximum temperatures throughout the GDL, as predicted by the single- and twophase models

Figure 15: Back pressure as a function of water stoichiometry for single- and two-phase flow

Figure 16: Standard deviation in mass flow per channel length as function of particle diameter

Figure 17: Mean, maximum and standard deviation in gas volume fraction inside the GDL as function of particle diameter

Figure 18: Mean and maximum temperature inside the GDL as a function of particle diameter 


\section{$837 \quad$ List of Tables}

838 Table 1: Superficial Reynolds number as a function of water stoichiometry for a current density of $1 \mathrm{~A} / \mathrm{cm}^{2}$

839 Table 2: Nominal operation conditions

840 


\begin{tabular}{|c|c|c|}
\hline Symbol & Description & Unit \\
\hline$\varepsilon$ & Volume porosity & - \\
\hline $\mathrm{s}$ & Engineering strain & - \\
\hline $\mathrm{P}$ & Pressure & $\mathrm{Pa}$ \\
\hline$\mu$ & Dynamic viscosity & Pas \\
\hline $\mathrm{K}$ & Viscous permeability & $\mathrm{m}^{2}$ \\
\hline$\rho$ & Density & $\mathrm{kg} / \mathrm{m}^{3}$ \\
\hline$\beta$ & Inertial Forchheimer coefficient & $1 / \mathrm{m}$ \\
\hline $\mathrm{u}$ & Superficial velocity & $\mathrm{m} / \mathrm{s}$ \\
\hline Q & Heat & $\mathrm{J}$ \\
\hline$T$ & Temperature & $\mathrm{K}$ \\
\hline $\mathrm{S}$ & Entropy & $\mathrm{J} / \mathrm{K}$ \\
\hline G & Gibbs free energy & $\mathrm{J}$ \\
\hline $\mathrm{H}$ & Enthalpy & $\mathrm{J}$ \\
\hline $\mathrm{h}$ & Specific enthalpy & $\mathrm{J} / \mathrm{kg}$ \\
\hline e & Specific internal energy & $\mathrm{J} / \mathrm{kg}$ \\
\hline $\mathrm{n}$ & Number of electrons transferred & - \\
\hline $\mathrm{F}$ & Faradays constant $=96485.3365$ & $\mathrm{C} / \mathrm{mol}$ \\
\hline $\mathrm{V}$ & Voltage & $\mathrm{V}$ \\
\hline$q$ & Specfic heat & $\mathrm{J} / \mathrm{mol}$ \\
\hline 1 & Current & A \\
\hline j & Current density & $\mathrm{A} / \mathrm{m}^{2}$ \\
\hline A & Area & $\mathrm{m}^{2}$ \\
\hline $\mathrm{D}$ & Diameter & $\mathrm{M}$ \\
\hline$\lambda$ & Stoichiometric factor & - \\
\hline $\mathrm{M}$ & Molecular weight & $\mathrm{kg} / \mathrm{mol}$ \\
\hline$\dot{\mathrm{m}}$ & Mass flow rate & $\mathrm{Kg} / \mathrm{s}$ \\
\hline $\operatorname{Re}$ & Reynolds number & - \\
\hline$a$ & Length & $\mathrm{m}$ \\
\hline $\mathrm{b}$ & Width & $m$ \\
\hline$U$ & True velocity & $\mathrm{m} / \mathrm{s}$ \\
\hline $\mathrm{S}$ & Source term & \\
\hline$\tau$ & Shear stress & $\mathrm{Pa}$ \\
\hline g & Gravitational acceleration vector & $\mathrm{m} / \mathrm{s}^{2}$ \\
\hline$M$ & Generalized momentum source term & $\mathrm{kg} / \mathrm{m}^{2} \mathrm{~s}^{2}$ \\
\hline $\mathrm{k}$ & Kinetic energy & $\mathrm{m}^{2} / \mathrm{s}^{2}$ \\
\hline$\omega$ & Turbulent eddy frequency & $1 / \mathrm{s}$ \\
\hline C & Turbulence model constant $=0.09$ & - \\
\hline$\beta$ & Turbulence model constant $=0.09$ & - \\
\hline$\beta^{\prime}$ & Turbulence model constant $=0.075$ & - \\
\hline$\sigma_{\rho}$ & Turbulent Schmidt number $=1$ & - \\
\hline$\alpha$ & Turbulence model constant $=5 / 9$ & - \\
\hline
\end{tabular}




\begin{tabular}{|l|l|l|}
\hline$C_{3}$ & Turbulence model constant $=1$ & - \\
\hline$C_{\mu p}$ & Turbulence model constant $=0.6$ & \\
\hline$S$ & Phase saturation or phase volume fraction & - \\
\hline$C_{D}$ & Drag coefficient & - \\
\hline$a_{c d}$ & Interfacial area density for the interphase drag force & $1 / \mathrm{m}$ \\
\hline$S_{d m}$ & Maximum packing value & - \\
\hline$C_{c d}$ & Momentum transfer coefficient for the interphase drag force & - \\
\hline$n$ & Genuchten model constant & - \\
\hline$m$ & Genuchten model constant & - \\
\hline$\lambda$ & Thermal conductivity & $\mathrm{W} / \mathrm{m} \mathrm{K}$ \\
\hline $\mathbf{n}$ & Normal vector & - \\
\hline$C_{p}$ & Specific heat capacity at constant pressure & $\mathrm{J} / \mathrm{kg} \mathrm{K}$ \\
\hline$\sigma$ & Surface tension & $\mathrm{N} / \mathrm{m}$ \\
\hline$\sigma$ & Standard deviation & \\
\hline$\mu$ & Mean & \\
\hline$V$ & Volume & $\mathrm{m}$ \\
\hline$m$ & Mass & $\mathrm{kg}$ \\
\hline
\end{tabular}

842 
Abbreviations

\begin{tabular}{|l|l|}
\hline PEM & Proton exchange membrane \\
\hline FC & Fuel cell \\
\hline EC & Electrolysis cell \\
\hline GDL & Gas diffusion layer \\
\hline CL & Catalyst layer \\
\hline MPL & Micro porous layer \\
\hline BP & Bipolar plate \\
\hline $\mathrm{Ti}$ & Titanium \\
\hline
\end{tabular}

845

846 


\section{Subscripts}

\begin{tabular}{|l|l|}
\hline 0 & Initial conditions \\
\hline rev & Reversible \\
\hline irr & Irreversible \\
\hline cell & Cell conditions \\
\hline neutral & Thermo-neutral conditions i.e. no heat is produced or consumed \\
\hline in & Inlet \\
\hline out & Outlet \\
\hline H & Hydraulic \\
\hline T & Turbulence \\
\hline k & Turbulent kinetic energy \\
\hline kb & Effect of buoyancy on turbulent kinetic energy \\
\hline$\omega k$ & Effect of buoyancy on turbulent frequency \\
\hline$\alpha$ & Phase \\
\hline rel & Relative \\
\hline D & Drag \\
\hline TD & Turbulent dispersion \\
\hline I & Liquid \\
\hline $\mathrm{g}$ & Gas \\
\hline $\mathrm{m}$ & Mixture \\
\hline C & Capillary \\
\hline cb & Capillary breakthrough \\
\hline e & Effective \\
\hline S & Solid \\
\hline E & External \\
\hline C & Cross section \\
\hline
\end{tabular}

848 